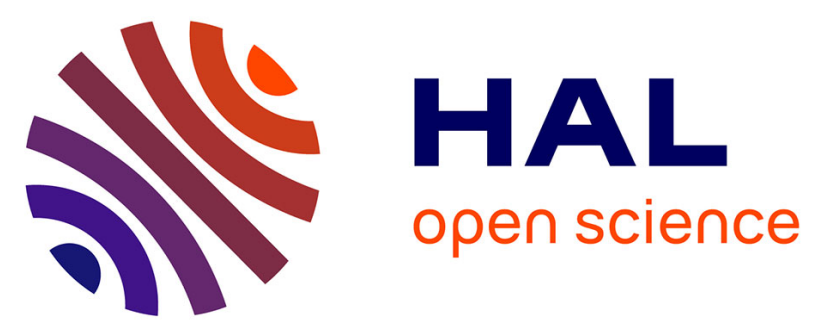

\title{
Density and temperatures of the upper martian atmosphere measured by stellar occultations with Mars Express SPICAM
}

François Forget, Franck Montmessin, Jean-Loup Bertaux, Francisco González-Galindo, Sébastien Lebonnois, Eric Quémerais, Aurélie Reberac, Emmanuel Dimarellis, Miguel A. López-Valverde

\section{To cite this version:}

François Forget, Franck Montmessin, Jean-Loup Bertaux, Francisco González-Galindo, Sébastien Lebonnois, et al.. Density and temperatures of the upper martian atmosphere measured by stellar occultations with Mars Express SPICAM. Journal of Geophysical Research. Planets, 2009, 114 (E1), pp.E01004. 10.1029/2008JE003086 . hal-00357038

\section{HAL Id: hal-00357038 https://hal.science/hal-00357038}

Submitted on 6 Feb 2016

HAL is a multi-disciplinary open access archive for the deposit and dissemination of scientific research documents, whether they are published or not. The documents may come from teaching and research institutions in France or abroad, or from public or private research centers.
L'archive ouverte pluridisciplinaire HAL, est destinée au dépôt et à la diffusion de documents scientifiques de niveau recherche, publiés ou non, émanant des établissements d'enseignement et de recherche français ou étrangers, des laboratoires publics ou privés. 


\title{
Density and temperatures of the upper Martian atmosphere measured by stellar occultations with Mars Express SPICAM
}

\author{
François Forget, ${ }^{1}$ Franck Montmessin, ${ }^{2}$ Jean-Loup Bertaux, ${ }^{2}$ Francisco González-Galindo, ${ }^{1}$ \\ Sébastien Lebonnois, ${ }^{1}$ Eric Quémerais, ${ }^{2}$ Aurélie Reberac, ${ }^{2}$ Emmanuel Dimarellis, ${ }^{2}$ \\ and Miguel A. López-Valverde ${ }^{3}$ \\ Received 22 January 2008; revised 29 July 2008; accepted 8 September 2008; published 28 January 2009.
}

[1] We present one Martian year of observations of the density and temperature in the upper atmosphere of Mars (between 60 and $130 \mathrm{~km}$ ) obtained by the Mars Express ultraviolet spectrometer Spectroscopy for Investigation of Characteristics of the Atmosphere of Mars (SPICAM). Six hundred sixteen profiles were retrieved using stellar occultations technique at various latitude and longitude. The atmospheric densities exhibit large seasonal fluctuations due to variations in the dust content of the lower atmosphere which controls the temperature and, thus, the atmospheric scale height, below $50 \mathrm{~km}$. In particular, the year observed by SPICAM was affected by an unexpected dust loading around $\mathrm{Ls}=130^{\circ}$ which induced a sudden increase of density above $60 \mathrm{~km}$. The diurnal cycle could not be analyzed in detail because most data were obtained at nighttime, except for a few occultations observed around noon during northern winter. There, the averaged midday profile is found to slightly differ from the corresponding midnight profile, with the observed differences being consistent with propagating thermal tides and variations in local solar heating. About $6 \%$ of the observed mesopause temperatures exhibits temperature below the $\mathrm{CO}_{2}$ frost point, especially during northern summer in the tropics. Comparison with atmospheric general circulation model predictions shows that the existing models overestimate the temperature around the mesopause (above 80 to $100 \mathrm{~km}$ ) by up to $30 \mathrm{~K}$, probably because of an underestimation of the atomic oxygen concentration which controls the $\mathrm{CO}_{2}$ infrared cooling.

Citation: Forget, F., F. Montmessin, J.-L. Bertaux, F. González-Galindo, S. Lebonnois, E. Quémerais, A. Reberac, E. Dimarells, and M. A. López-Valverde (2009), Density and temperatures of the upper Martian atmosphere measured by stellar occultations with Mars Express SPICAM, J. Geophys. Res., 114, E01004, doi:10.1029/2008JE003086.

\section{Introduction}

[2] The thermal structure and the atmospheric dynamics of Martian atmosphere above $50 \mathrm{~km}$ remains almost unexplored. The atmosphere has been monitored for several years by the thermal infrared spectrometers and radio science experiments aboard Mars Global Surveyor (MGS) [M. D. Smith et al., 2001; Smith, 2004; Hinson et al., 2004] and Mars Express [Grassi et al., 2005; Pätzold et al., 2006]. Unfortunately, these observations have been limited to the lower atmosphere, up to $50 \mathrm{~km}$ at most. With the Mars Climate Sounder aboard Mars Reconnaissance Orbiter (MRO) [McCleese et al., 2007], this range is now being extended up to $70-80 \mathrm{~km}$. Above this level, the Martian

\footnotetext{
${ }^{1}$ Laboratoire de Météorologie Dynamique, Institut Pierre-Simon Laplace, Université Paris 6, Paris, France.

${ }^{2}$ Service d'Aéronomie, Institut Pierre-Simon Laplace, Verrières-leBuisson, France.

${ }^{3}$ Instituto de Astrofísica de Andalucía, Granada, Spain.

Copyright 2009 by the American Geophysical Union. 0148-0227/09/2008JE003086
}

atmosphere is poorly known. Only a few in situ measurements are available, including the 5 density profiles from the Viking, Pathfinder and Mars Exploration Rovers entries [Seiff and Kirk, 1977; Magalhães et al., 1999; Withers and Smith, 2006] and the density measurements obtained during the aerobraking phases of the MGS, Mars Odyssey and MRO missions [Keating et al., 1998, 2003, 2007].

[3] However, the Martian atmosphere between 60 and $130 \mathrm{~km}$ is of very high interest. On the one hand, the few observations available have revealed a rich and complex dynamics combining various kinds of waves probably interacting with the mean circulation [Magalhães et al., 1999; Angelats $i$ Coll et al., 2004; Forbes et al., 2002]. On the other hand, information on this part of the atmosphere is vital to prepare spacecraft missions performing aerobraking, aerocapture or EDL (entry, descent and landing).

[4] Here we present the first remote sensing observations of the density and temperature of the Martian atmosphere between 50 and $130 \mathrm{~km}$ altitude, measured by the Mars express UV spectrometer Spectroscopy for Investigation of Characteristics of the Atmosphere of Mars (SPICAM) using 


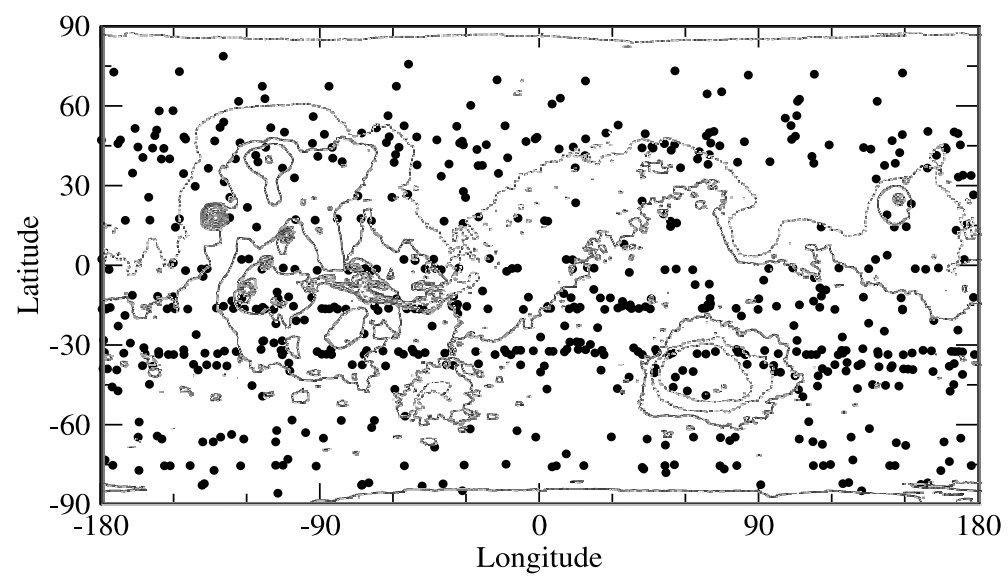

a)

Longitude

b)

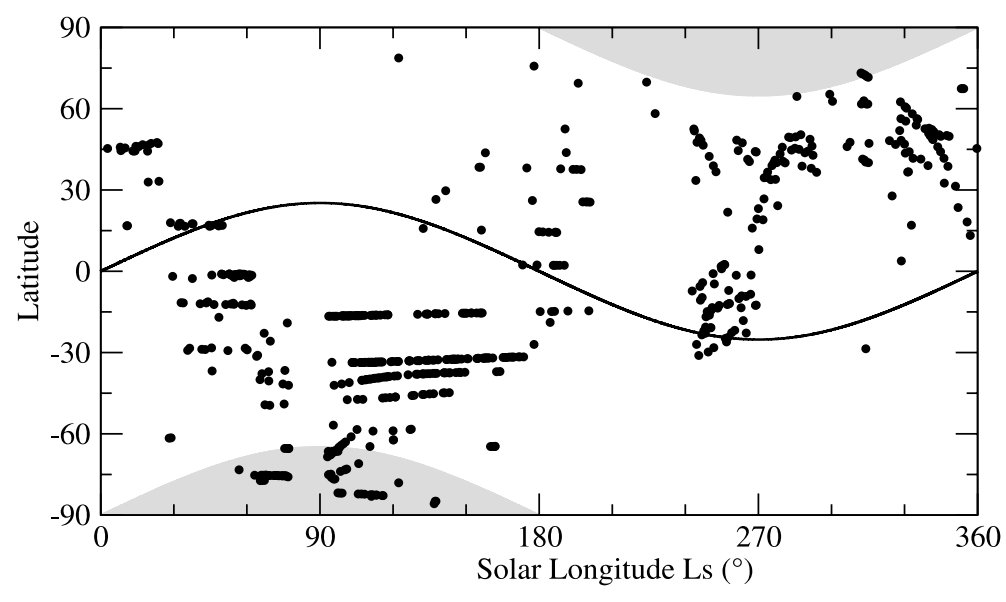

Figure 1. The spatial and seasonal distribution of the 616 SPICAM solar occultations used in this paper. (a) Locations of the occultations superimposed on a topography map of Mars. (b) The latitudinal distribution of the occultations as a function of season (Ls, areocentric longitude of the sun, with Ls $=0^{\circ}$ at northern spring equinox). The black solid line shows the latitude of the subsolar point. Shaded areas illustrate the extension of the polar nights.

the stellar occultation technique. A total of 616 usable density profiles obtained throughout one Mars year are analyzed and temperature profiles are derived from the density measurements.

\section{SPICAM Stellar Occultation Data Set}

[5] The SPICAM instrument and its various modes of operation were described by Bertaux et al. [2006], while the technique of stellar occultation and the processing of the SPICAM observations are described by Quémerais et al. [2006]. Briefly, to observe Mars middle atmosphere, SPICAM continuously observes a selected star while the spacecraft moves around the planet so that the star can be observed setting or rising through the atmosphere. When the star is high above the horizon, the light spectrum of the star is recorded free of any atmospheric absorption. When the star is seen through the atmosphere, the spectrum is modified by the absorption of all atmospheric constituents integrated over the line of sight from the instrument to the star. By analyzing such variations in the $110-310 \mathrm{~nm}$ wavelength range with $\mathrm{a} \simeq 1.5 \mathrm{~nm}$ resolution, SPICAM provides information about the profile of aerosols [Montmessin et al., 2006], ozone [Lebonnois et al., 2006], and $\mathrm{CO}_{2}$ (this paper).
One occultation typically lasts a few minutes. The location of the tangential points only moves by a few tens of kilometers during the observation.

[6] In the present study, we analyze data from the 616 usable stellar occultation profiles obtained over more than one Martian year in 2004, 2005, and early 2006. After one early profile obtained at the beginning of the mission during orbit 17 (14 January 2004, Ls $=332.8^{\circ}$ ), data were recorded regularly starting on orbit $134\left(\mathrm{Ls}=353.4^{\circ}, 22\right.$ February 2004) until orbit 2779 ( $\mathrm{Ls}=23.3^{\circ}, 12$ March 2006), with one late single profile obtained during orbit 2888 (Ls = $37.6^{\circ}$ ), 11 April 2006. Figure 1 shows the locations of the stellar occultations and their seasonal distribution. The observations cover the entire planet, although the latitudinal coverage depends on the season with significantly more observations during fall and winter in each hemisphere. This results from the concentration of hot UV stars along the galactic plane combined with the Mars Express orbit variations (with its periapsis latitude slowly varying with time) and the fact that observations were preferentially performed on the night side where solar light scattered by aerosols and reflected by the surface could not affect the measure. Figure 2 shows the solar local time for all the observations as a function of latitude and season (Ls). Most stellar 
a)
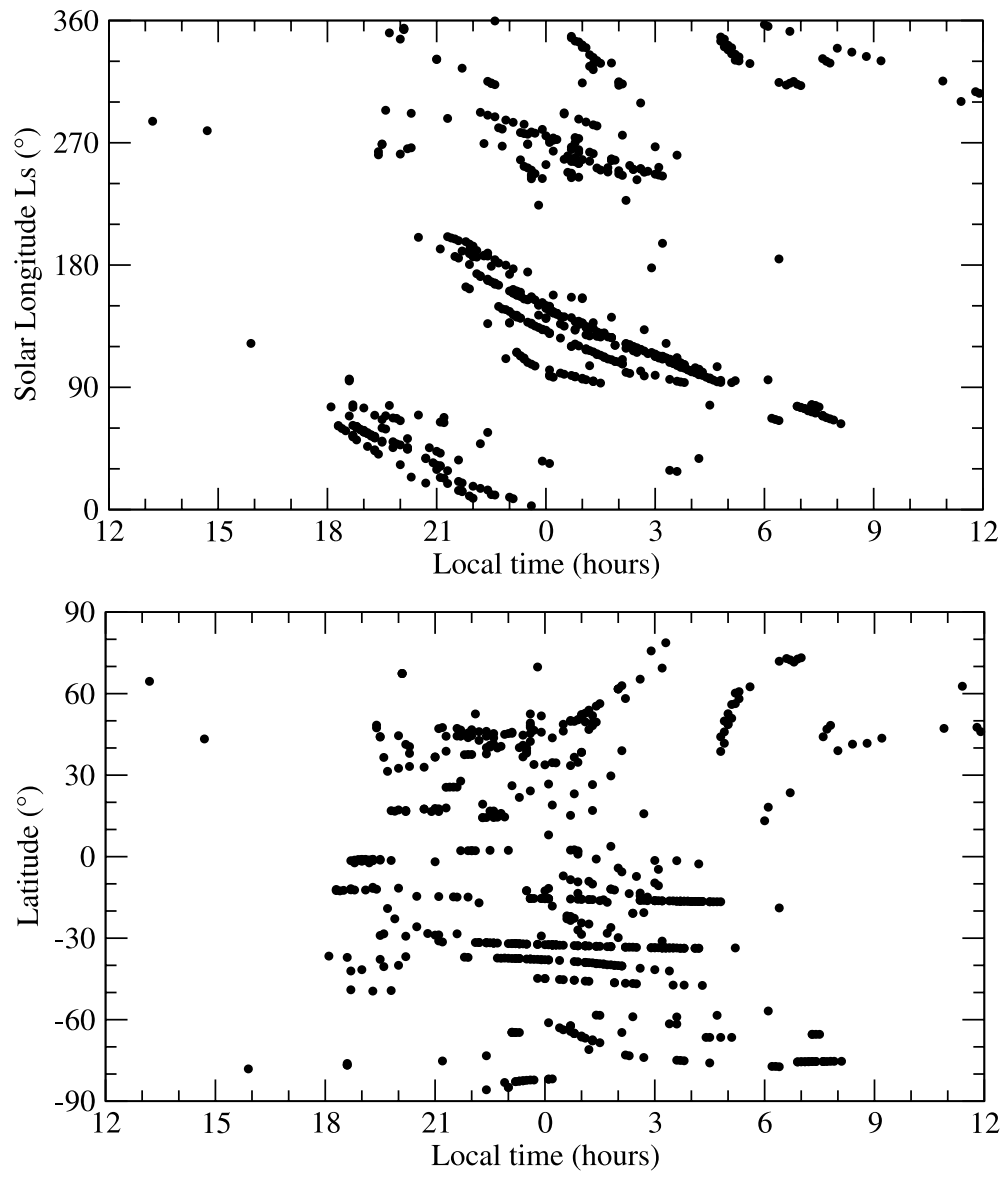

Figure 2. Local true solar time at the retrieved profiles locations as function of latitude and season (Ls). The local true solar time indicates the time of day of the observations. By definition it is noon at the subsolar meridian, and one sol is divided into $24 \mathrm{~h}$.

occultation profiles were obtained during the night between 1800 and 0600 , with only 7 profiles outside this period on the dayside during northern winter.

\section{Data Retrieval}

\subsection{Density Profile}

[7] $\mathrm{CO}_{2}$, the main constituent of the Martian atmosphere absorbs the UV light emitted by the occulted star between 120 and $190 \mathrm{~nm}$. Only hot stars emit enough UV to be used for $\mathrm{CO} 2$ absorption. With the knowledge of the cross section from Yoshino et al. [1996], and assuming BeerLambert law for the gaseous absortion, one can deduce the amount of $\mathrm{CO}_{2}$ present between SPICAM and the star, as explained by Quémerais et al. [2006]. This amount, the slant density, is the integral of the local density over the line of sight. The local density profile can thus be derived from the slant densities by performing a mathematical inversion. We used the onion peeling approach with a Tikhonov regularization method [Tikhonov and Arsenin, 1977] as described in details by Quémerais et al. [2006]. Compared to the work by Quémerais et al. [2006], however, we have improved the forward radiative transfer model. They had used a model resolution of $1.5 \mathrm{~nm}$ to match the SPICAM spectral resolution and save computing time in the fitting process. However, the transmission computed with such averaged cross sections can differ from the average of the transmission obtained with infinite spectral resolution. Here, we performed our radiative transfer calculations at the highest possible resolution provided by the spectroscopic database $(0.005 \mathrm{~nm})$. Also, in this paper, the slant densities profiles were initially smoothed by using a running average function with a vertical width of $10 \mathrm{~km}$ applied to the logarithm of the slant densities. Only data with noise error on slant densities lower than $20 \%$ were used. Figures $3 a, 3 b$, and $3 \mathrm{c}$ show three typical $\mathrm{CO}_{2}$ density profile retrieved at various seasons. The error bars combine several effects. First, they include the instrumental noise which is detailed by Quémerais et al. [2006]. By smoothing the slant densities during our retrieval, we average spectra and thus improve the noise-related error (at the cost of degrading the vertical resolution). This is now taken into account in our error bars, with a typical contribution from the instrumental noise around 3 to $8 \%$ between 70 and $120 \mathrm{~km}$.

[8] Second, the error bars are asymmetric to represent a possible bias due to uncertainties in the spectroscopic data mostly due to variations with temperature. The $\mathrm{CO}_{2}$ cross sections of Yoshino et al. [1996] are only available at 195 and $295 \mathrm{~K}$. In this paper, we used the $195 \mathrm{~K}$ data, which can be significantly warmer than the atmosphere usually observed by SPICAM. To better understand how a departure from $195 \mathrm{~K}$ can affect our retrieval, we performed sensitivity 
a)
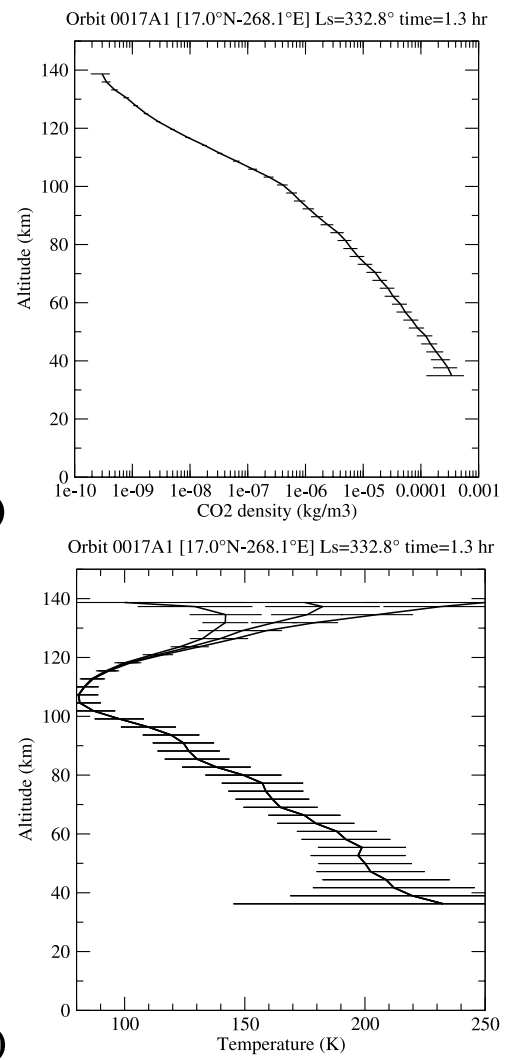

b)
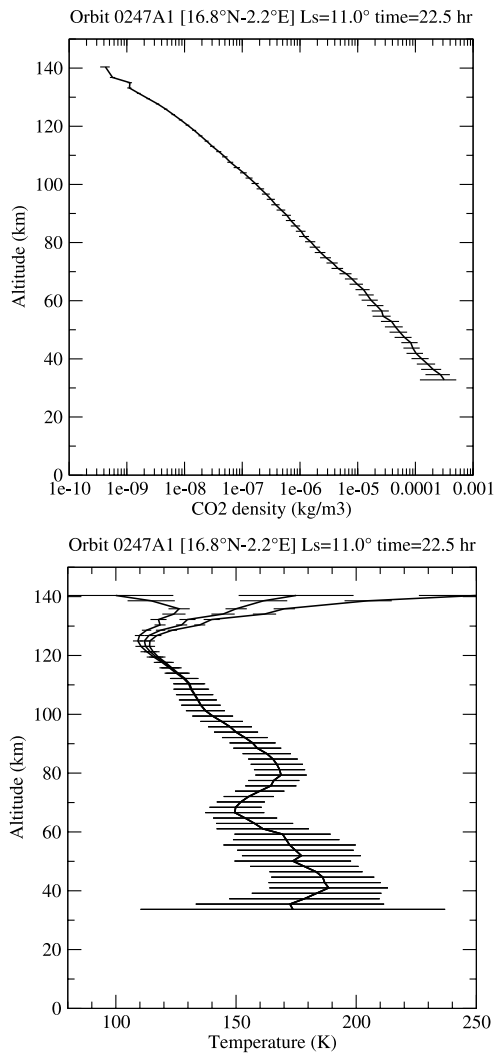

Orbit $1909 \mathrm{~A} 2\left[-4,2^{\circ} \mathrm{N}-222 \cdot 1^{\circ} \mathrm{E}\right] \mathrm{Ls}=247.1^{\circ}$ time $=2.0 \mathrm{hr}$

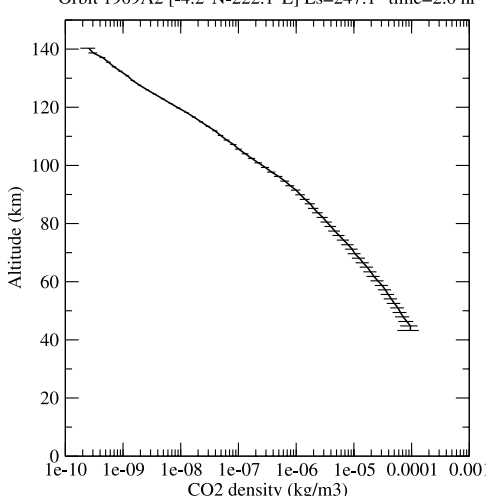

c)
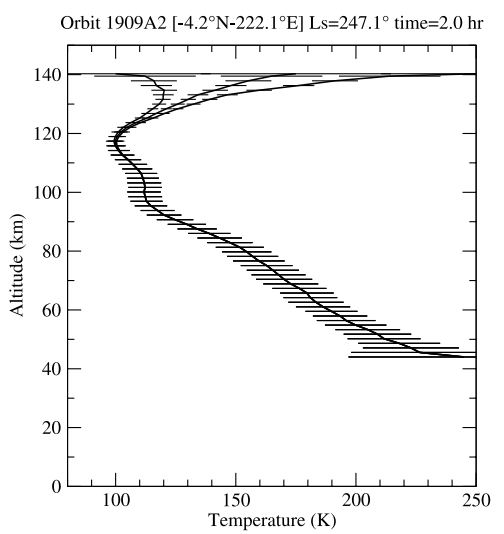

Figure 3. Examples of (top) three typical SPICAM CO 2 density profiles and (bottom)the corresponding derived temperature profiles. The error bars illustrate the instrumental and retrieval model errors and a possible bias due to uncertainties on $\mathrm{CO}_{2}$ cross sections (see text). In each cases, three temperature profiles retrieved with top temperatures of 100,175 . and $250 \mathrm{~K}$ are shown.

studies using the $295 \mathrm{~K}$ spectroscopic data. They showed that the impact of temperature is stronger when observing larger slant densities (i.e., lower atmospheric levels) because the $\mathrm{CO}_{2}$ absorption cross sections sensitivity to temperature is mostly significant at wavelengths larger than $160 \mathrm{~nm}$ (with a maximum around $190 \mathrm{~nm}$ [see Quémerais et al., 2006, Figure 17]). The retrieval is sensitive to this part of the spectra only for slant densities larger than $10^{19}$ molecules per $\mathrm{cm}^{2}$ (i.e., altitude below about $100 \mathrm{~km}$ ). For smaller slant densities the effect is small, with an average difference of $7 \%$ between the retrievals performed with the 195 and $295 \mathrm{~K}$ data set. Above $10^{19} \mathrm{~cm}^{-2}$, the difference increase linearly with the log of slant density and reaches $50 \%$ for slant densities equal or larger than $10^{22} \mathrm{~cm}^{-2}$ (i.e., below $50 \mathrm{~km}$ ). Extrapolating this sensitivity below $195 \mathrm{~K}$ may be hazardous. Nevertheless, taking into account the typical Martian temperatures at various levels, we have assumed a $5 \%$ bias for slant densities lower than $10^{19}$ $\mathrm{cm}^{-2}$ and a $20 \%$ error above $10^{22} \mathrm{~cm}^{-2}$ with a linear transition with the log of slant density in between. Because the $\mathrm{CO}_{2}$ absorption decrease with temperature and because the upper atmosphere observed by SPICAM is colder than $195 \mathrm{~K}$, the corresponding bias correspond to an underestimation of the density. Below $60 \mathrm{~km}$, it is likely that the presence of airborne dust adds an additional uncertainty which is difficult to estimate [Quémerais et al., 2006]. Absorption by dust is the limiting factor of the method at low altitudes (no more star signal), while at high altitudes the limiting factor is the $\mathrm{CO} 2$ slant density. Altogether, we suspect that the density retrieved by SPICAM below $50 \mathrm{~km}$ are often strongly underestimated, and not reliable.

\subsection{Temperature Profiles}

[9] Temperature profiles can be derived from the density profiles assuming that the atmosphere is in hydrostatic equilibrium [Quémerais et al., 2006; Korablev et al. 2001]. In practice, the integration is performed from the top of the density profile to the bottom, to avoid the amplification of errors resulting from the decrease of density when going upward. The temperature at the top of the density profile (around $140 \mathrm{~km}$ ) is not known. In this study we assumed that it ranged between 100 and $250 \mathrm{~K}$, in agreement with the available in situ observations [Seiff and Kirk, 1977; Magalhães et al., 1999] and model results [Bougher et al., 1999; Angelats $i$ Coll et al., 2005]. Figures 3d, 3e, and 3f show typical temperature profiles corresponding to the density profiles shown above. In each cases, three temperature profiles are retrieved assuming top temperatures of 100,175 , and $250 \mathrm{~K}$. The three curves are superimposed below $120 \mathrm{~km}$. It is safe to assume that the retrieved temperature profile is insensitive to the assumed top boundary temperature below this level. As for the density, the error bars account for the instrumental noise (typically 3 to $6 \mathrm{~K}$ at $115 \mathrm{~km}, 7$ to $15 \mathrm{~K}$ at $70 \mathrm{~km}$ ) and the possible bias resulting from the underestimation of density due to spectroscopic data uncertainties. We estimate it by adding the systematic 

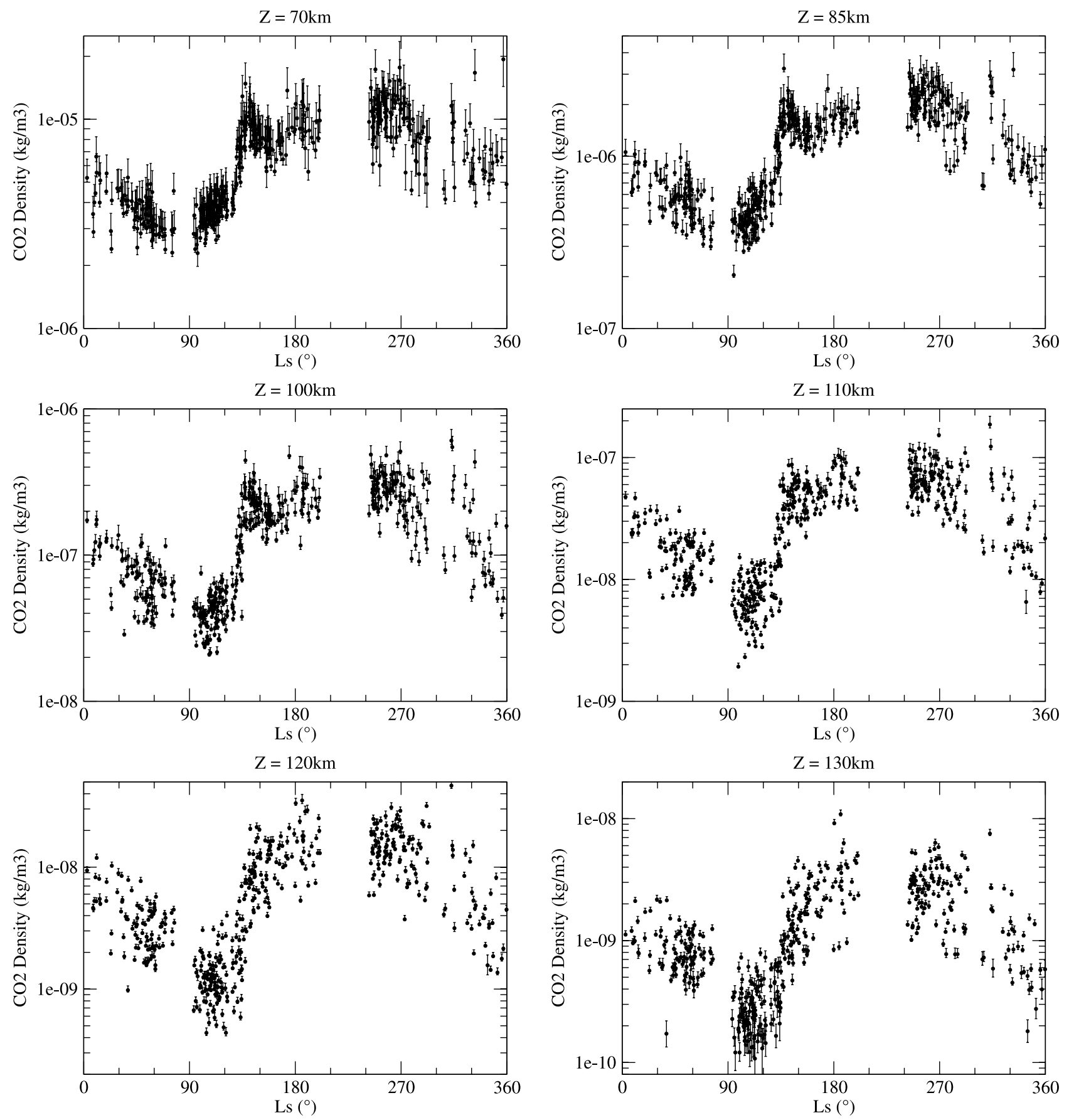

Figure 4. $\mathrm{CO}_{2}$ density as a function of season at various altitudes above the Mars zero datum (areoid). Only the data obtained below $50^{\circ}$ latitude are shown.

bias mentioned above to the density profile, and use the resulting profile to retrieve temperature. The associated shift remains below $3 \mathrm{~K}$ between 60 and $110 \mathrm{~km}$. Below, dust may affect the quality of the results. In any cases, we believe that SPICAM temperatures below $0.1 \mathrm{~Pa}$ (or $70 \mathrm{~km}$ ) are often strongly overestimated, and not reliable.

\section{Seasonal Variations}

\subsection{Influence of the Lower Atmosphere on Density}

[10] The atmospheric densities observed by SPICAM primarily vary with seasons. Figure 4 shows a compilation of the density measurements interpolated at various altitudes above the Mars geoid (areoid) as defined by the Mars Orbiter Laser Altimeter (MOLA) team in the IAU2000 cartographic frame [D. E. Smith et al., 2001]. Density varies by a factor of about 3 at $70 \mathrm{~km}$ and more at higher altitudes. Density is minimum around southern winter solstice $(\mathrm{Ls}=$ $90^{\circ}$ ) and maximum around Mars perihelion $\left(\mathrm{Ls}=251^{\circ}\right)$. This was expected. To first order, it corresponds to the variations of the atmospheric temperature in the lower atmosphere, as observed for instance by the Thermal Emission Spectrometer (TES) aboard MGS [M. D. Smith et al., 2001, Smith, 2004]. Indeed, the density $\rho$ at a given 


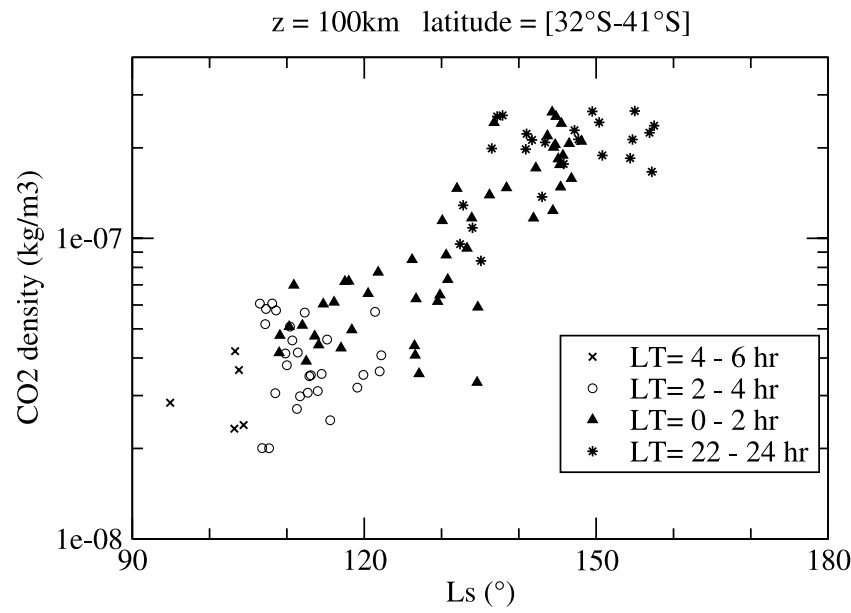

Figure 5. A subset of the data shown on Figure 4. Only data from the $\left[32^{\circ} \mathrm{S}-41^{\circ} \mathrm{S}\right]$ latitude range are shown at altitude $100 \mathrm{~km}$ and for northern summer. Data obtained within the same local time range are represented by a similar symbol. The large density variation observed even during the restricted [0-2] local time range shows that the observed variation is due to a seasonal change rather than a diurnal event.

altitude $z$ is proportional to pressure $p(\rho=p / R T$, with $R=$ $192 \mathrm{~m}^{2} \mathrm{~s}^{-2} \mathrm{~K}^{-1}$ the gas constant and $T$ the temperature). Pressure primarily depends on the mean scale height $H$ of the atmosphere below this level (roughly, $p=p_{0} e^{-z / H}$, with $p_{0}$ pressure at $\left.z=0 \mathrm{~km}\right) . H$ is proportional to the mean temperature $T\left(H=R T / g\right.$ with $g=3.72 \mathrm{~m} \mathrm{~s}^{-2}$ the acceleration of gravity). TES data show that during years without global dust storms, the tropical and midlatitude atmospheric temperature from a few kilometers above the surface up to at least $50 \mathrm{~km}$ typically fluctuates with a total amplitude of about $20 \mathrm{~K}$ between a minimum near Ls $=70$ $90^{\circ}$ and a maximum around $\mathrm{Ls}=250^{\circ}$. This variation results from the fluctuation of the solar flux due to Mars orbit eccentricity and from the seasonal variations of dust loading in the Martian atmosphere. This amplitude is in agreement with the density variations observed by SPICAM at $70 \mathrm{~km}$. For instance a mean temperature varying between $160 \mathrm{~K}$ and $180 \mathrm{~K}$ below $70 \mathrm{~km}$ would create density variation by a factor of about 3 at $70 \mathrm{~km}$, as observed by SPICAM.

[11] An unexpected feature in the SPICAM density data is the sudden increase of density around Ls $=130^{\circ}$, which matched no known events in the previous years. Before further investigation, however, we had to rule out the possibility that the variations corresponded to a change in local time rather than Solar Longitude, since both parameters varied simultaneously during that period in the observations (Figure 2).

[12] Figure 5 shows the evolution of a subset of the SPICAM density data at $100 \mathrm{~km}$ acquired in the $41^{\circ} \mathrm{S}-$ $32^{\circ} \mathrm{S}$ latitudinal belt. The data are represented by different symbols depending on their local time. An inspection of the density data obtained during the restricted $[0-2]$ local time range shows that the density did strongly vary with the season even within this local time windows. We can thus conclude that the change in density was mostly related to a seasonal event, probably in the atmosphere below. However, no significant increase of atmospheric temperatures was recorded at that particular season by TES during the three previous Martian years [M. D. Smith et al., 2001, Smith, 2004]. Unfortunately, TES atmospheric record stopped on 31 August $2004\left(\mathrm{Ls}=81^{\circ}\right)$, before the density increase observed by SPICAM. Nevertheless, data are available from Mars Express Planetary Fourier Spectrometer (PFS) (D. Grassi, personal communication, 2006), Mars Odyssey Themis (M. D. Smith, personal communication, 2007) and from the two Mars Exploration Rover (MER) on the surface [Smith et al., 2006]. They reveal that Mars experienced a significant and unusual dust storm event around Ls $=130^{\circ}$ which affected a large part of the planet (including both rover sites) and raised the dust optical depth at $1075 \mathrm{~cm}^{-1}$ $(9.3 \mu \mathrm{m})$ to near unity (Figure 6). This corresponds to a visible dust opacity of more than 2 , which is enough to raise the temperature in the lower atmosphere and thus the density around $70 \mathrm{~km}$ significantly. More generally, the
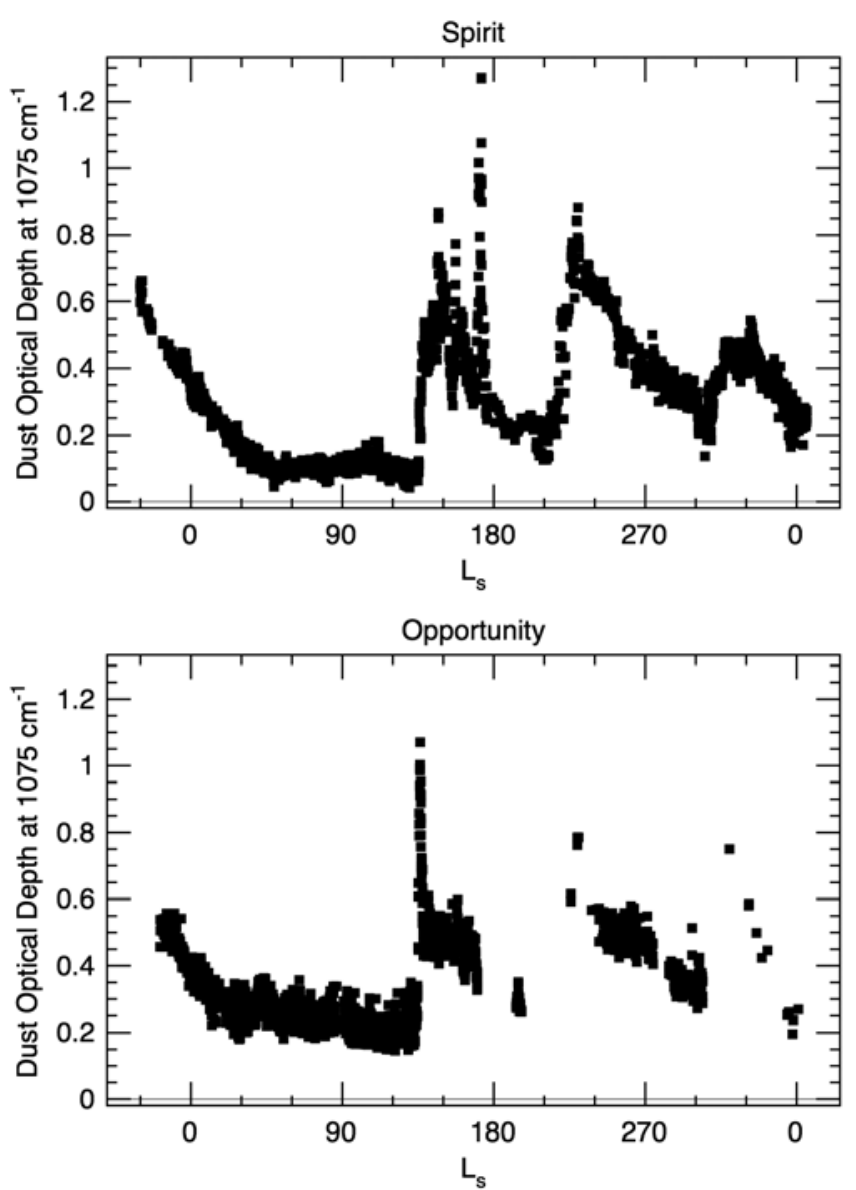

Figure 6. Dust optical depth at $1075 \mathrm{~cm}^{-1}(9.3 \mu \mathrm{m})$ as function of season for the Mars Exploration Rovers (top) Spirit and (bottom) Opportunity as retrieved by Smith et al. [2006] using Mini-TES spectrometer observations. The data were obtained during the same year than the SPICAM data discussed in this paper. The fluctuations of atmospheric dust optical depth appear to be correlated with the density variations in the upper atmosphere observed by SPICAM and shown in Figure 4. From Smith et al. [2006]. 
a)

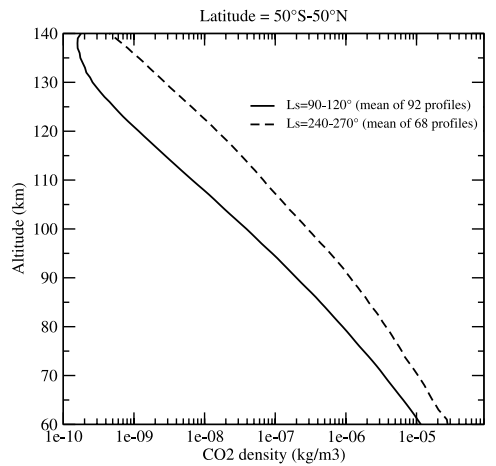

b)

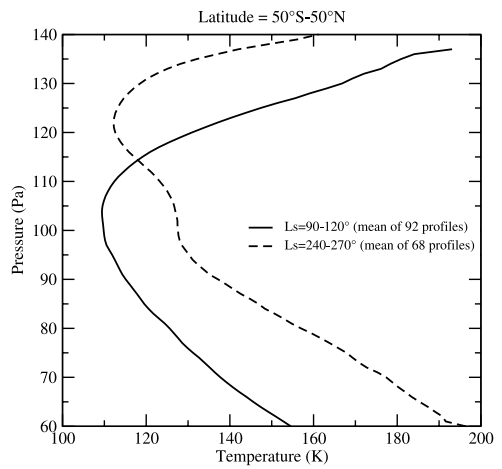

c)

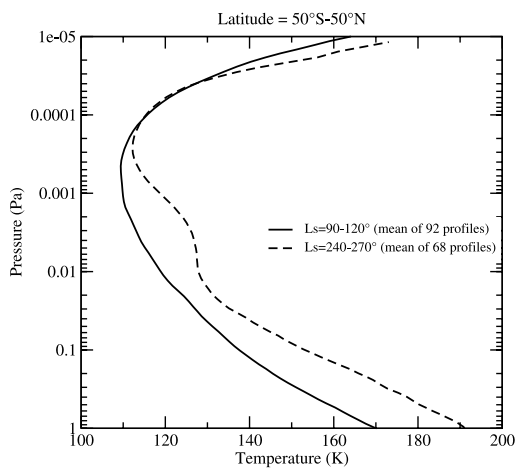

Figure 7. Comparison of the mean vertical density and temperature structure of the upper atmosphere observed around northern summer solstice ( $\mathrm{Ls}=90^{\circ}-120^{\circ}$, solid line) and winter solstice (Ls $=240^{\circ}$ $270^{\circ}$, dashed line). Each profile is obtained by averaging observations interpolated at the same altitude or pressure level.

comparison of SPICAM density data shown in Figure 4 with the MER dust observations from Figure 6 suggest that most of the density seasonal variations result from variations in the dust loading in the lower atmosphere.

\subsection{Seasonal Fluctuations in the Upper Atmosphere}

[13] Figure 4 shows that density varied annually by a factor of about $3,5,7,13,20$ at respectively $70,85,100$, 110 and $120 \mathrm{~km}$. The fact that the relative amplitude of the seasonal variations significantly increase with altitude suggest that the thermal structure of the upper Martian atmosphere also varied with season. This is first illustrated in Figure 7 which shows the mean density and temperature profiles for the period of minimum and maximum density $\left(\mathrm{Ls}=90^{\circ}-120^{\circ}\right.$ and $\left.\mathrm{Ls}=240^{\circ}-270^{\circ}\right)$. When the temperature profiles are plotted as a function of altitude (Figure $7 \mathrm{~b}$ ), the two mean profiles are clearly shifted by about $20 \mathrm{~km}$. This primarily reflects the fact that the lower atmosphere was warmer and more expanded during the $\mathrm{Ls}=240^{\circ}-270^{\circ}$ period and that the same altitude does not correspond to the same pressure depending on the season. In the upper atmosphere, temperature fields must be analyzed and compared in pressure coordinate. Pressure $p$ can be calculated from the SPICAM data assuming that $p=T \rho R / q$, with $\rho$ the $\mathrm{CO}_{2}$ density and $q$ the $\mathrm{CO}_{2}$ mixing ratio (we assumed $q=0.953$ ). Figure $7 \mathrm{c}$ presents the two profiles plotted as a function of pressure. It shows that even in pressure coordinate, the Ls $=240^{\circ}-270^{\circ}$ profile remained 10 to $20 \mathrm{~K}$ warmer than the $\mathrm{Ls}=90^{\circ}-120^{\circ}$ profile up to the $0.0005 \mathrm{~Pa}$ level $(100-120 \mathrm{~km})$. This could be explained by the fact that the mean solar flux at Mars is $40 \%$ higher around $\mathrm{Ls}=240^{\circ}-270^{\circ}$ compared to the Ls $=90^{\circ}-120^{\circ}$. The heating of the middle atmosphere resulting from the absorption of the near infrared solar radiation by the atmospheric $\mathrm{CO}_{2}$ should thus have varied accordingly.

[14] The general seasonal behavior of atmospheric temperature observed by SPICAM at various pressure levels is shown on Figure 8. In spite of the spread of the data, one can identify the relative variations discussed above. At 0.1 $\mathrm{Pa}(70-80 \mathrm{~km})$ and $0.01 \mathrm{~Pa}(85-100 \mathrm{~km})$, temperatures are minimum around $\mathrm{Ls}=90^{\circ}$ and maximum near $\mathrm{Ls}=270^{\circ}$. Above these levels, the behavior is less clear, consistently with terrestrial observations which show seasonal variations of the mesopause temperatures of only 10 to $20 \mathrm{~K}$ [von
Zahn and Höffner, 1996; States and Gardner, 2000]. The $0.0001 \mathrm{~Pa}$ plot $(115-130 \mathrm{~km})$ shows highest temperatures around $\mathrm{Ls}=55^{\circ}$, for unknown reasons. In particular, no particular solar activity (EUV or X) was recorded during this period (early February 2005).

\section{Diurnal Variations}

[15] As shown in Figure 2, most of the SPICAM data were obtained during nighttime, except for a few daytime profiles acquired during winter in the northern hemisphere. Figure 9 shows two averages of profiles obtained in the same latitudinal range $\left(40^{\circ} \mathrm{N}-50^{\circ} \mathrm{N}\right)$ during the $\mathrm{Ls}=270^{\circ}-$ $330^{\circ}$ period, but at opposite solar local time. Above the $0.002 \mathrm{~Pa}$ level (around $110 \mathrm{~km}$ ) the mean daytime profile is about $15 \mathrm{~K}$ warmer than the nighttime profile, as expected at the bottom of the thermosphere where the energy balance is controlled by solar EUV and near infrared heating. Below that level, the two profiles are very close. The observed wave structures seems to be anticorrelated, suggesting that they are due to thermal tides of opposite phase. Such a plot reminds of the two Viking entry temperature profiles [Seiff and Kirk, 1977] which were similarly obtained at somewhat opposite local times and in which anticorrelated temperature oscillations were also already attributed to the "adiabatic compressional heating and expansional cooling associated with vertically propagating atmospheric thermal tides" [Zurek et al., 1992; Seiff and Kirk, 1977].

\section{Spatial Variations}

\subsection{Latitudinal Variations}

[16] As expected, the latitudinal variations of atmospheric density observed by SPICAM between 70 and $120 \mathrm{~km}$ primarily reflect the variations in temperature in the lower atmosphere. In particular, the density is observed to systematically decrease in the winter mid and high latitudes. Some examples of this behavior are presented along with model comparisons in section 7.2.

[17] Figure 10 shows the distribution of SPICAM temperatures retrieved at various atmospheric levels shortly after southern winter solstice $\left(\mathrm{Ls}=90^{\circ}-120^{\circ}\right)$ as a function of latitude. In spite of the spread of the data, one can see that the 0.1 and $0.01 \mathrm{~Pa}$ temperatures are characterized by a 20 

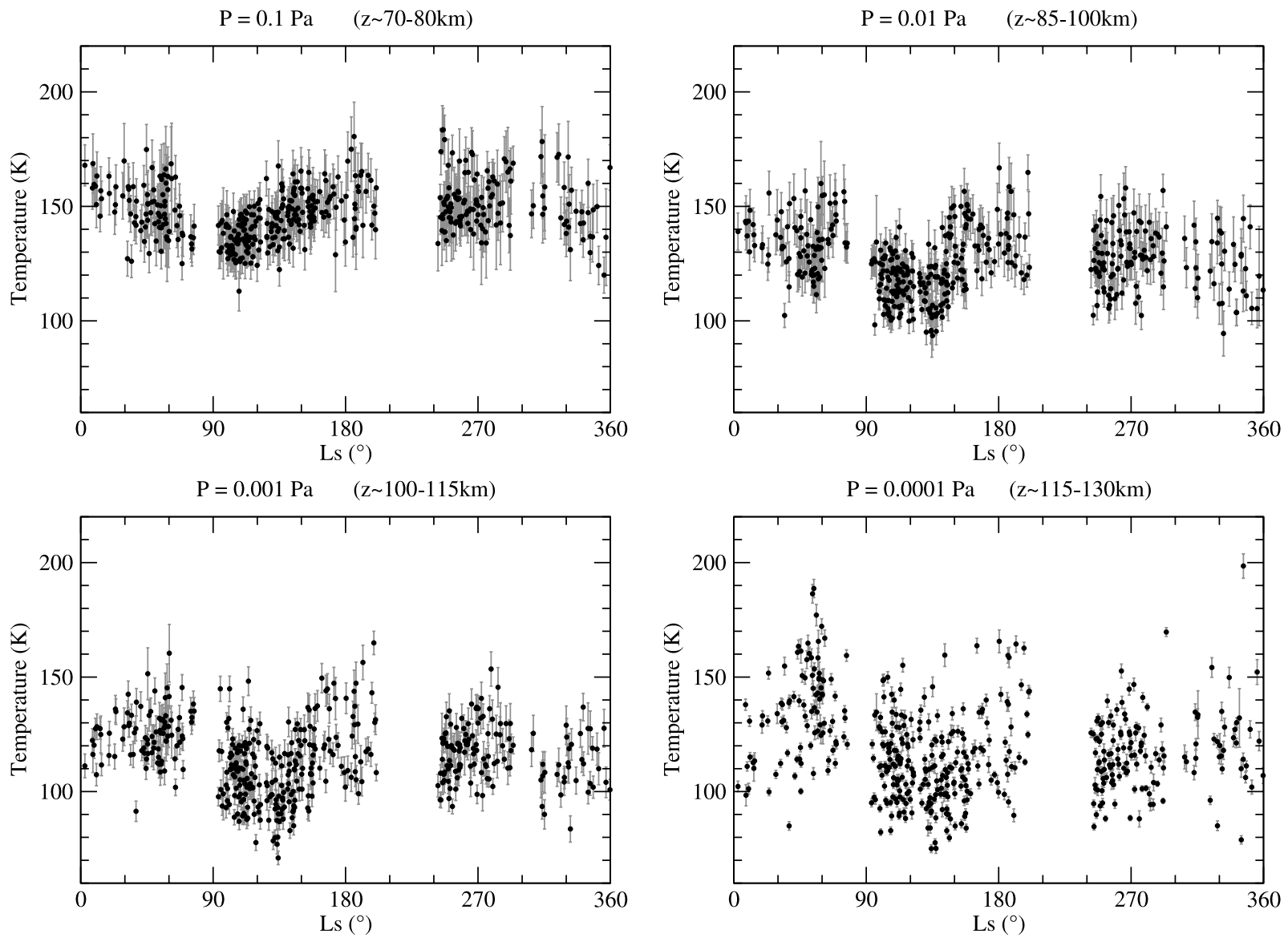

Figure 8. Temperature retrieved between $50^{\circ} \mathrm{S}$ and $50^{\circ} \mathrm{N}$ plotted as a function of season (Ls) and interpolated at four pressure levels. The absolute error bars shown are large, but we believe that the relative variations are meaningful. Depending on the season, $0.1 \mathrm{~Pa}$ corresponds to altitudes around 70$80 \mathrm{~km}, 0.01 \mathrm{~Pa}$ to $85-100 \mathrm{~km}, 0.001 \mathrm{~Pa}$ to $100-115 \mathrm{~km}$, and $0.0001 \mathrm{~Pa}$ to $115-130 \mathrm{~km}$.

to $30 \mathrm{~K}$ south polar warming. Such a warming has been predicted by General Circulation Models [Forget et al., 1999]. It is thought to result from adiabatic compression in descending winds induced by a convergence of mass in the upper atmosphere, primarily forced by thermal tides at this particular season. Similar or stronger warming have been observed in the northern polar night around $100-130 \mathrm{~km}$ by the Mars Odyssey spacecraft during its aerobraking period [see Bougher et al., 2006, and references therein]. In the southern hemisphere, the aerobraking observations are less clear. Data were obtained by Mars Global Surveyor [Bougher et al., 2006; Keating et al., 2003] and Mars Reconnaissance Orbiter [Keating et al., 2007]. Both spacecraft detected a cooling at $120-130 \mathrm{~km}$ [Bougher et al., 2006, 2007] but MRO measured a $10 \mathrm{~K}$ warming at 110 $\mathrm{km}$ [Keating et al., 2007] on the nightside. When plotted in altitude coordinate (not shown) SPICAM nightside observations are consistent with this observation, and suggest that if MRO had been able to make measurements at $90 \mathrm{~km}$ and $80 \mathrm{~km}$, it would have been able to detect a polar warming larger than $20 \mathrm{~K}$, at least on the nightside.

\subsection{Longitudinal Variations}

[18] The densities measured around $100-130 \mathrm{~km}$ by the aerobraking Mars Global Surveyor accelerometer at fixed

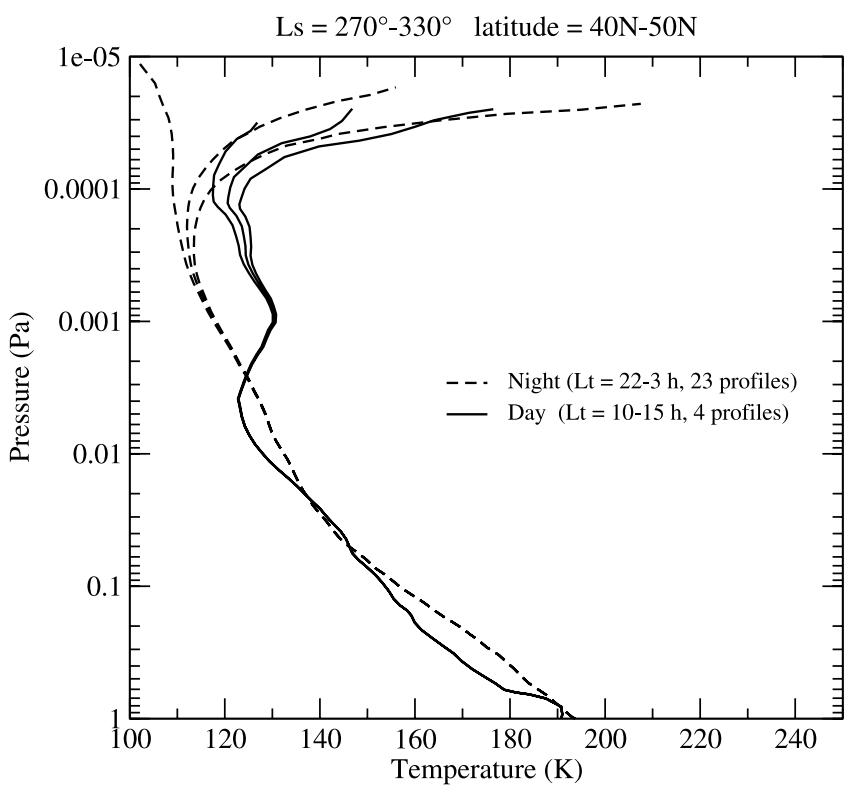

Figure 9. Day-night temperature variations observed by SPICAM in the winter northern midlatitudes. The curves are the average of 23 and 4 profiles retrieved at about the same local time and latitude. 

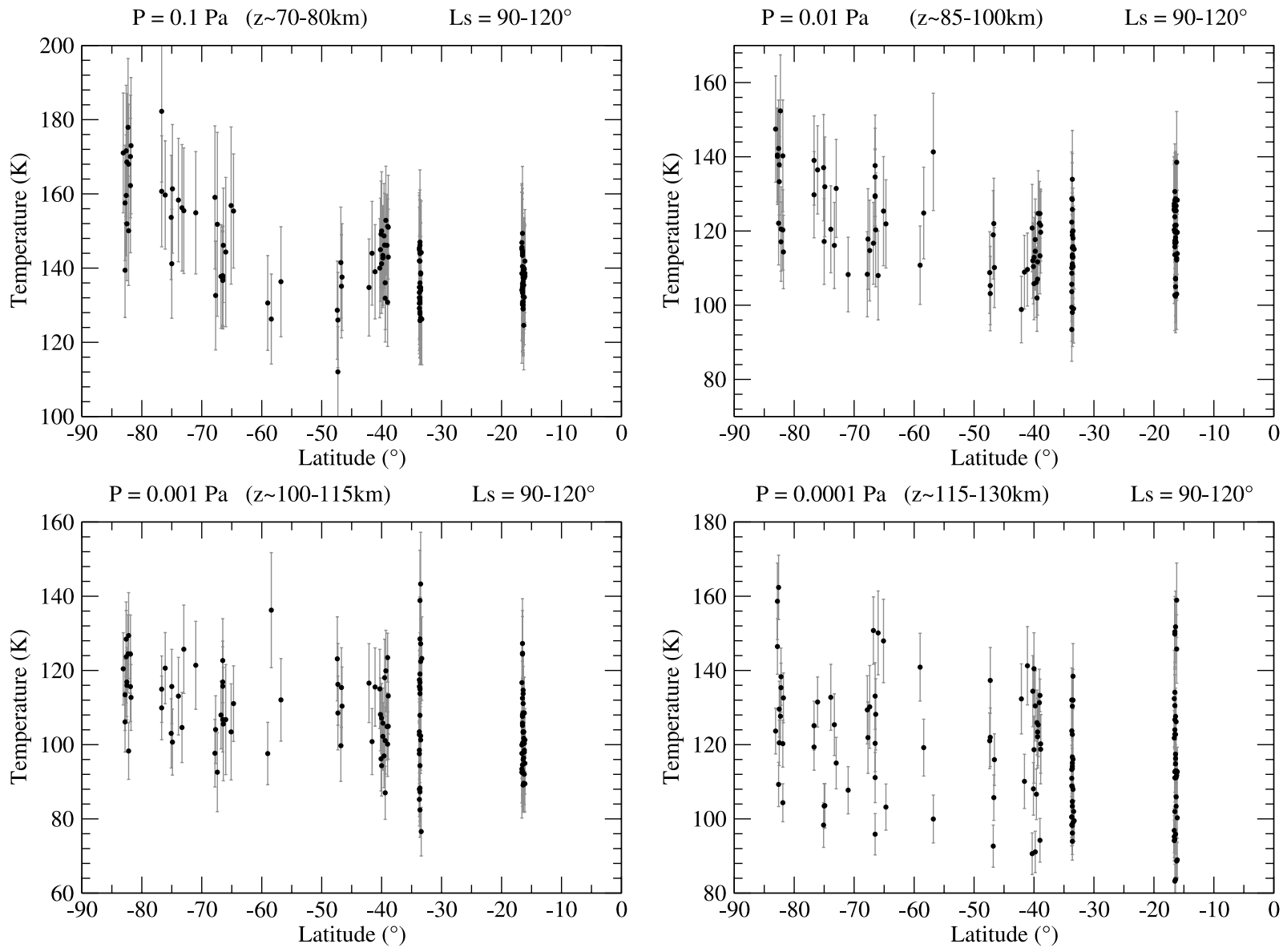

Figure 10. Latitudinal temperature variations in early southern winter $\left(\mathrm{Ls}=90^{\circ}-120^{\circ}\right)$ interpolated at four pressure levels. Note the $30 \mathrm{~K}$ polar warming above the $0.01 \mathrm{~Pa}(\sim 90 \mathrm{~km})$ level.

local time and latitude were often characterized by interesting longitudinal variations first interpreted as possible stationary planetary waves [Keating et al., 1998], and later attributed to eastward propagating waves of diurnal and semidiurnal frequencies [Forbes and Hagan, 2000; Wilson, 2002, Angelats $i$ Coll et al., 2004]. On this basis, we looked for similar structures in the SPICAM data obtained at similar local time and season, but at different longitude. No clear structure could be identified.

\section{Comparison With General Circulation Model Calculations}

\subsection{Laboratoire de Météorologie Dynamique General Circulation Model}

[19] To help interpret the SPICAM observations, we used the Laboratoire de Météorologie Dynamique (LMD) general circulation model (GCM) [Forget et al., 1999] which has been extended to the thermosphere [Angelats $i$ Coll et al., 2005]. The simulations used in this paper are based on a version of the model with 50 layers extending from about $5 \mathrm{~m}$ above the surface to $710^{-10} \mathrm{~Pa}$ (above $250 \mathrm{~km}$ ) and an horizontal resolution of $3.75^{\circ}$ in latitude by $5.675^{\circ}$ in longitude. In the lower and middle atmosphere it includes the radiative heating due to the absorption of solar radiation by dust and $\mathrm{CO}_{2}$ (in the near infrared) as well as the cooling induced in the $15 \mu \mathrm{m}$ thermal IR band of
$\mathrm{CO}_{2}$. Nonlocal thermodynamic equilibrium (LTE) effects are taken into account at high altitude non-LTE effects are known to be important at these altitudes for the radiative balance [López-Puertas and López-Valverde, 1995], and are included in the GCM in a parameterized form [López-Valverde et al., 1998; López-Valverde and López-Puertas, 2001].

[20] Molecular viscosity and thermal conduction, which plays a significant role in the thermosphere, are parameterized. Chemical species have been added to the simulations as described by González-Galindo et al. [2005]. There are a total of 11 components in the carbon, oxygen and hydrogen families that are transported, diffused and modified through chemical reactions. Specifically, the chemical species included are $\mathrm{CO}_{2}, \mathrm{CO}, \mathrm{O}_{2}, \mathrm{O}\left({ }^{3} \mathrm{P}\right), \mathrm{O}\left({ }^{1} \mathrm{D}\right), \mathrm{H}_{2}, \mathrm{H}$, $\mathrm{OH}, \mathrm{H}_{2} \mathrm{O}, \mathrm{HO}_{2}, \mathrm{H}_{2} \mathrm{O}_{2}$. Molecular nitrogen and Argon are also included but are treated as inert and have no part in the chemical reaction process. In the upper atmosphere, the model accounts for 22 chemical reactions between the 11 chemically active species. Molecular diffusion is taken into account with a state of the art approach in which all species diffuse simultaneously using the exact theory of multicomponent molecular diffusion [Angelats $i$ Coll et al., 2005]. The heating of the thermosphere by UV and EUV radiation is calculated using the model described by González-Galindo et al. [2005]. It includes the absorption by $\mathrm{CO}_{2}, \mathrm{O}_{2}$ and atomic oxygen, as well as by all the other 

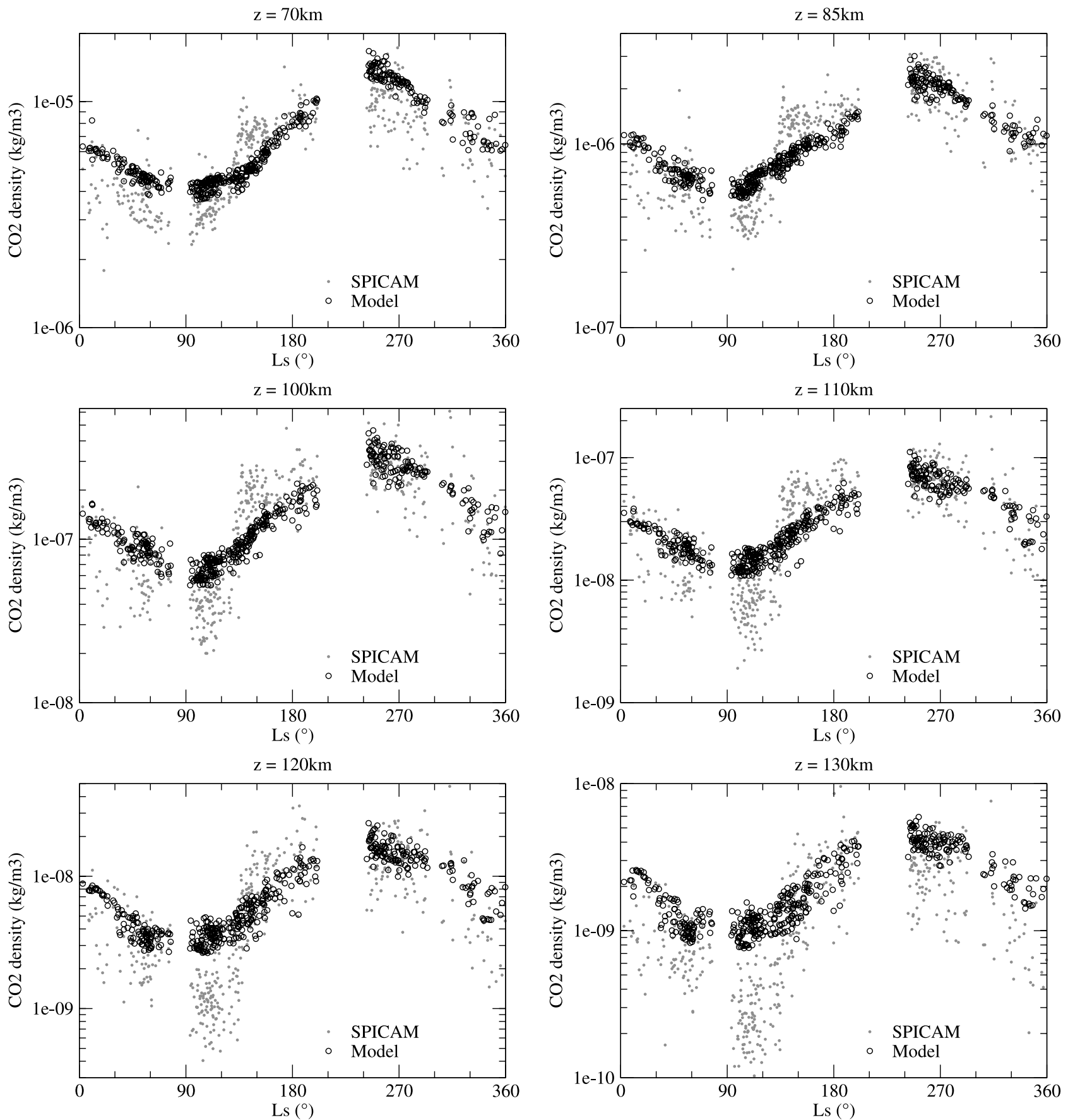

Figure 11. Comparison of SPICAM observations plotted as a function of season as in Figure 4 with GCM predictions at the same location and time (GCM data are from our "reference" 1999-2001 TES dust scenario). Except during the unexpected dusty period between $\mathrm{Ls}=140^{\circ}$ and $\mathrm{Ls}=180^{\circ}$, the GCM tends to overestimate the density observed by SPICAM.

minor species of the model in the spectral range between 0.1 and $337.7 \mathrm{~nm}$.

[21] Below 50-70 km, the modeled thermal structure of the atmosphere is primarily forced by the amount of airborne dust, which is known to be highly variable seasonally and from year to year. Above $100-120 \mathrm{~km}$, it also depends on the UV and extreme UV solar input which typically varies with the seasonal change of sun distance and with the 11 years solar cycle.
[22] In this paper, our "reference" simulation is based on a climatology of the dust as observed by Mars Global Surveyor TES between 1999 and June 2001 [M. D. Smith et al., 2001, Smith, 2004], a Martian year thought to be typical. It is topped by a thermosphere computed assuming solar averaged conditions regarding the EUV flux, which is a realistic proxy for the 2004-2005 period observed by SPICAM. In addition to this baseline scenario, we have used (1) a cold "low dust" scenario corresponding to an 

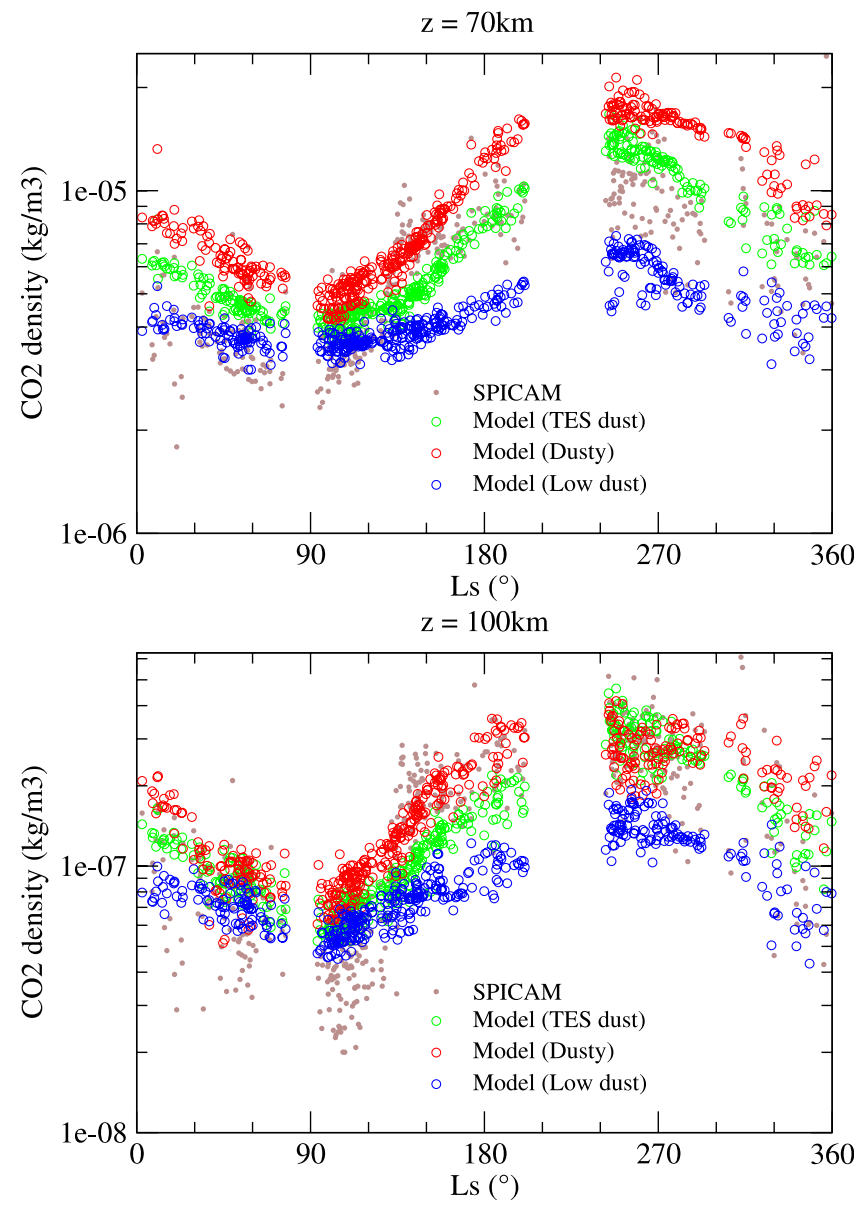

Figure 12. Same as Figure 11 for two altitudes and with GCM predictions obtained with three different dust scenarios in order to illustrate the variability of density at high altitude resulting from fluctuations in the low atmosphere dust loading.

extremely clear atmosphere (visible dust opacity $\tau=0.1$ at $700 \mathrm{~Pa}$ ), topped with a "solar minimum" thermosphere, and (2) a warm "dusty" extreme scenario corresponding to an atmosphere dustier than observed outside global dust storms $\left(\tau=0.7+0.3 \cos \left(L_{S}+80^{\circ}\right)\right.$ at $\left.700 \mathrm{~Pa}\right)$, topped with a "solar maximum" thermosphere. Statistical comparisons with three Martian years of TES data, radio occultation data and PFS data indicate that outside global dust storms period, the observed low atmosphere temperatures are always within a few kelvins from the GCM temperatures simulated with the reference scenario [Montabone et al., 2006; Millour et al., 2007], and systematically above and below the GCM cold and warm simulations.

\subsection{Analysis of the Density Variations With the GCM}

[23] Figure 11 shows a comparison of SPICAM observations plotted as a function of season (as in Figure 4) with GCM prediction at the same location and time. The GCM densities are interpolated from $30^{\circ} \mathrm{Ls}$ average values at the same local time. Therefore the effect of thermal tides is included whereas the transient day-to-day variability is completely smoothed out. To first order, the GCM densities roughly follow the observed seasonal evolution. The obser- vations are more scattered than the modeled values, probably because of transient waves. The model underestimates densities between $\mathrm{Ls}=140^{\circ}$ and $\mathrm{Ls}=180^{\circ}$, certainly because of the unusual dust loading observed in 2004 and not included in the 2000-2001 dust scenario used to force the GCM simulations. However, outside this period, the predicted densities are in most case higher than observed. The discrepancy is significant at $70 \mathrm{~km}$, and increase at higher altitude. Could that be due to a lower atmosphere less dusty and less warm than expected? To assess this hypothesis, and better estimate the impact of dust variations on the high atmosphere densities, we first compared the observations with results from the "dusty" and "low dust" GCM simulations described above. Figure 12 presents a comparison of the SPICAM density data at 70 and $100 \mathrm{~km}$ with the corresponding GCM predictions obtained with the "reference", "low dust" and "dusty" scenarios described above. It shows that variations in dust loading could explain a part

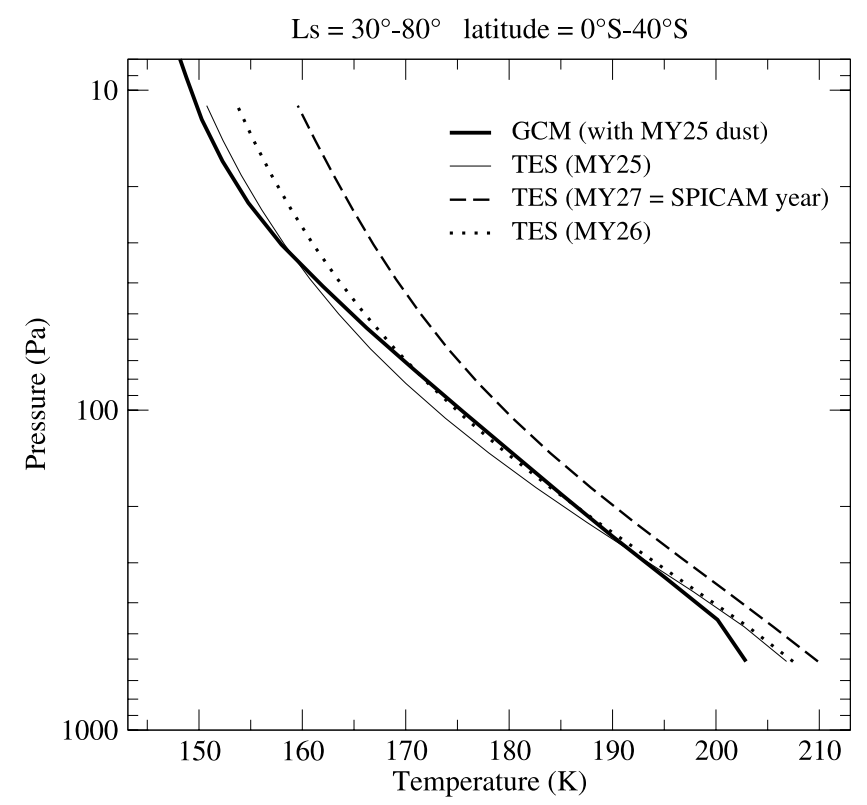

Figure 13. Comparison of low atmosphere temperature profiles obtained by TES from Mars Global Surveyor [Smith, 2004] at 2am (Martian solar local time) in the past 3 Martian years with GCM predictions obtained using the "reference" dust scenario based on observation of dust loading during Martian year 25 (MY25). For each profile, data were averaged over all longitudes, latitude $0^{\circ} \mathrm{S}-40^{\circ} \mathrm{S}$ and over Ls $=30-80^{\circ}$. This corresponds to SPICAM observations where density significantly lower than predicted by the GCM were observed in the atmosphere above. Surprisingly, however, the lower atmosphere observed by TES was then dustier and warmer than assumed by the GCM, not colder. Thus the thermal structure of the atmosphere below $40 \mathrm{~km}$ cannot explain the discrepancy between the GCM and SPICAM observations. Martian years (MY) are numbered according to the calendar proposed by R. T. Clancy [Clancy et al., 2000] which starts on 11 April $1955\left(\mathrm{Ls}=0^{\circ}\right)$. The curve shown above thus correspond to the periods 3 August 2000 to 24 November 2000 (MY25), 26 June 2002 to 13 October 2002 (MY26), and 8 May 2004 to 29 August 2004 (MY27). 

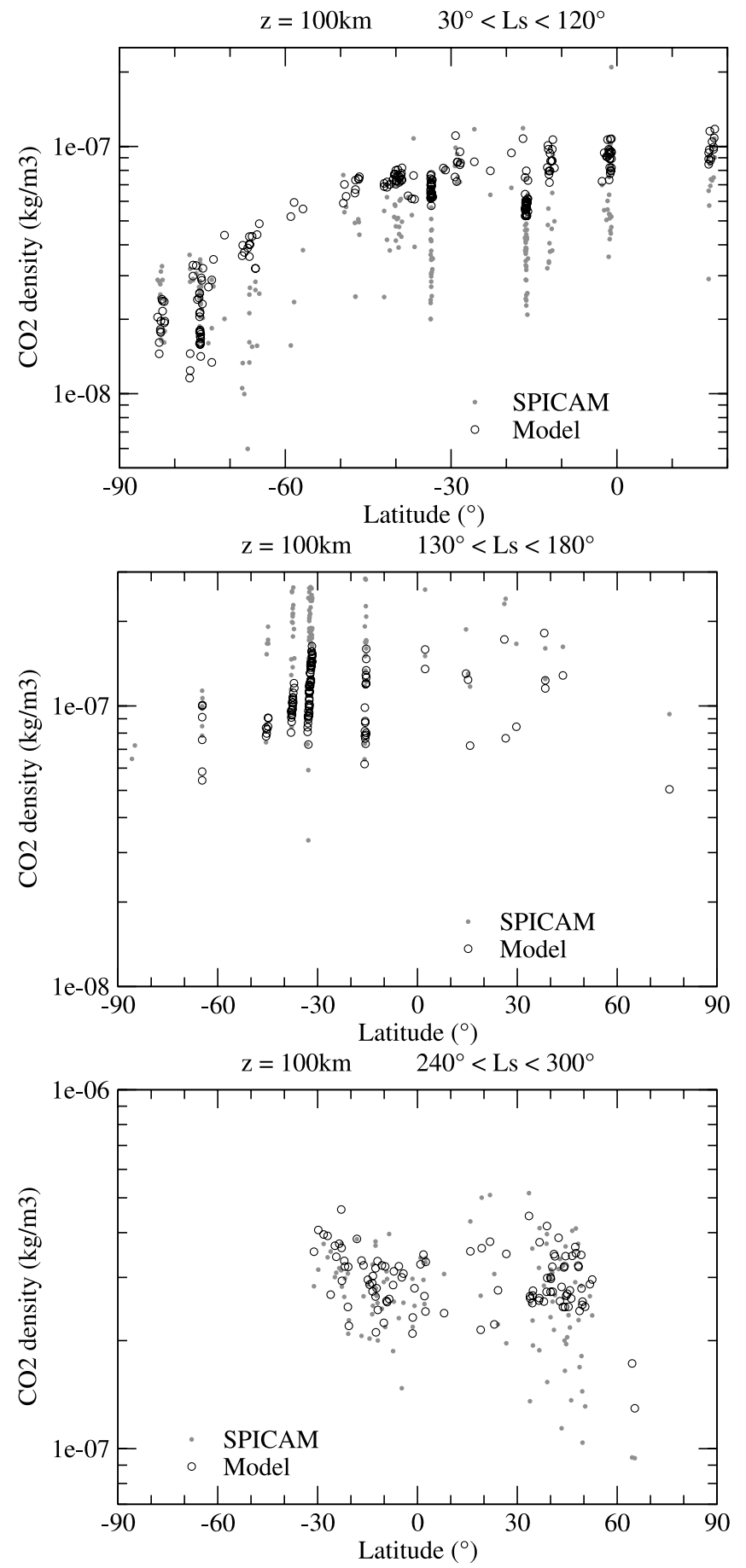

Figure 14. Comparison of SPICAM density at $100 \mathrm{~km}$ plotted as a function of latitude with GCM predictions at the same location and time. Three seasons are shown. GCM data are from our "reference" 1999-2001 TES dust scenario.

of the discrepancy, but not all. In particular SPICAM density observations around $\mathrm{Ls}=60-120^{\circ}$ remains significantly lower than values obtained with the "low dust" extreme scenario $(\tau=0.1$ at $700 \mathrm{~Pa})$. Was the Martian atmosphere clearer than that in 2004? Fortunately, this can be investigated using the TES observations which are available until 31 August $2004\left(\mathrm{Ls}=81^{\circ}\right)$. Figure 13 shows the TES mean temperature profile in the $0^{\circ} \mathrm{S}-40^{\circ} \mathrm{S}$ latitudinal belt observed by SPICAM, during Ls $=30-80^{\circ}$ (northern fall). It is compared to similar temperature profiles obtained in the previous 2 years by TES and to the GCM prediction. The comparison shows that the GCM is in good agreement with the TES observations from 2000, as expected, and reveals that at the time of the SPICAM observations, the lower atmosphere was actually dustier and warmer than in the previous years! Within that context, the low densities observed by SPICAM as low as $70 \mathrm{~km}$ are difficult to reconcile with the GCM prediction and the TES observations. One possibility is that the middle atmosphere between $10 \mathrm{~Pa}$ and $0.1 \mathrm{~Pa}$ (i.e., between 40 and $70 \mathrm{~km}$ ) was colder than predicted by the GCM. Using the hydrostatic equation, one can show that the $30 \%$ density difference observed at $70 \mathrm{~km}$ on Figure 4 would be explained by a $10 \mathrm{~K}$ temperature difference between 40 and $70 \mathrm{~km}$ (assuming equal density at $40 \mathrm{~km}$, which may not be the case according to Figure 13, however).

[24] Latitudinal variations of density can also be detected by SPICAM and compared to GCM predictions. The observed density at $100 \mathrm{~km}$ for the periods Ls $=30-$ $120^{\circ}, \mathrm{Ls}=130-180^{\circ}$ and $\mathrm{Ls}=240-300^{\circ}$ are plotted as a function of latitude in Figure 14. The density measured around southern winter solstice $\left(\mathrm{Ls}=30-120^{\circ}\right.$ ) decreases by about 1 order of magnitude between the tropics and the polar night, certainly because of the decrease of temperature in the atmosphere below. This is correctly predicted by the GCM. At other seasons, no clear structure can be identified (unfortunately no SPICAM data are available in the northern winter polar night). Nevertheless, the GCM does a reasonable job to predict the spread and the possible variations seen in the observations. One exception are the northern winter midlatitudes around $\mathrm{Ls}=240-300^{\circ}$ : Above $30^{\circ} \mathrm{N}$, the GCM often overestimates the density.

\subsection{Unexpected Low Temperature at the Homopause}

[25] The overestimation of the observed densities by the GCM strongly increases with altitude. This suggests that the modeled scale heights of the atmosphere are generally larger than in reality, and that the GCM temperatures above $70 \mathrm{~km}$ are overestimated. This is confirmed in Figures 15 and 16 which present comparisons between SPICAM retrieved temperatures and GCM predictions. Figure 15 shows a comparison for all data between $50^{\circ} \mathrm{S}$ and $50^{\circ} \mathrm{N}$ plotted as a function of season at four pressure levels. At $0.1 \mathrm{~Pa}$ (around 70-80 km), the GCM temperatures agree well with the observations (given the absolute error bars) and somewhat predict the subtle seasonal evolution described before. In particular, the GCM does simulate the observed increase of temperature between $\mathrm{Ls}=100^{\circ}$ and $\mathrm{Ls}=150^{\circ}$ in spite of the fact that as discussed above, the GCM could not account for the unusual increase of airborne dust observed at that time in 2004. We can thus conclude that to first order, the $\mathrm{Ls}=130^{\circ}$ dust storm did not directly affect the temperature above the $0.1 \mathrm{~Pa}$ level. Between $\mathrm{Ls}=180^{\circ}$ and $\mathrm{Ls}=360^{\circ}$ (northern fall and winter, the dusty season), a few observations exhibit temperatures 20 to $30 \mathrm{~K}$ larger than predicted, possibly because high altitude aerosols affected the temperature retrieval.

[26] At higher altitude, the observed temperatures are lower than predicted, often by 40 to $60 \mathrm{~K}$ ! This is better 

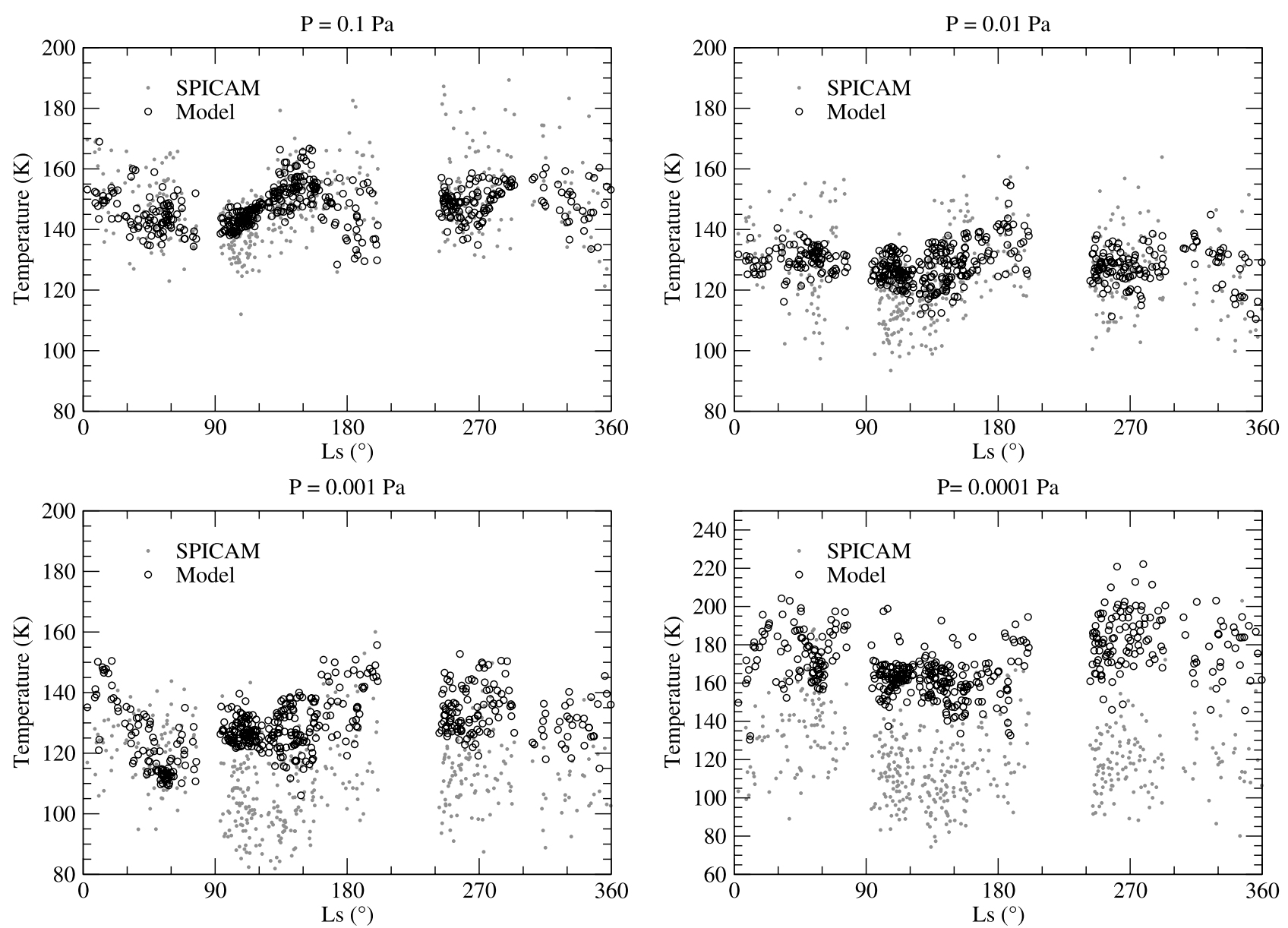

Figure 15. Comparison of the SPICAM temperature observations shown in Figure 8 with GCM predictions at the same location and time. Data obtained between $50^{\circ} \mathrm{S}$ and $50^{\circ} \mathrm{N}$ are plotted as a function of season (solar longitude Ls). GCM predictions are from our "reference" 1999-2001 TES dust scenario simulation. Depending on the season, $0.1 \mathrm{~Pa}$ corresponds to altitudes around $70-80 \mathrm{~km}, 0.01 \mathrm{~Pa}$ to $85-$ $100 \mathrm{~km}, 0.001 \mathrm{~Pa}$ to $100-115 \mathrm{~km}$, and $0.0001 \mathrm{~Pa}$ to $115-130 \mathrm{~km}$.

illustrated in Figure 16 which shows a selection of 12 averaged profiles representing all the latitudes and seasons observed by SPICAM, compared to GCM predictions obtained with our various dust and solar EUV scenarios. In many cases, the GCM strongly overestimates the observed temperatures around $0.001 \mathrm{~Pa}(85-100 \mathrm{~km})$. The shape of the temperature profiles suggest that the differences result from the fact that (1) mesopause temperatures are overestimated by the model and (2) mesopause altitudes tend to be underestimated by the model.

[27] What could be the origin of such modeling errors? Radiative processes are thought to control the global mean temperature and altitude of the mesopause [Bougher et al., 1994]. Other processes (molecular conduction, chemical and dynamical processes) can influence the temperature structure, allowing individual temperature profiles to be far from radiative equilibrium [States and Gardner, 2000]. However, the systematic nature of the differences observed in the temperature of the mesopause seems to point to the IR radiative balance as the most likely responsible. This hypothesis is reinforced by the intercomparisons between the LMD GCM and the Mars Thermospheric General Circulation Model (MTGCM) (see, for example, Bougher et al. [1999] for a description of this thermospheric GCM). These two different models use the same parameterization for the IR emissions by $\mathrm{CO}_{2}$, based on the work by LópezValverde and López-Puertas [2001], and both predict similar temperatures in the mesopause, well above those observed by SPICAM. One of the most uncertain approximations included in this parameterization is the use of a constant atomic oxygen profile (which has a cooling effect on $\mathrm{CO}_{2}$, see below), instead of the "actual" atomic oxygen distribution predicted by the GCM. The reason of this approximation is twofold. First, little is known about the precise distribution of atomic oxygen in the upper mesosphere/lower thermosphere. The available data show an important variability [Stewart et al., 1992]. In the absence of a climatology of atomic oxygen in the upper atmosphere, an abundance appropriate for average conditions was taken from Nair et al. [1994]. Second, although the GCM now includes a photochemical model, that was not the case at the time this parameterization was developed. No variations in the concentrations of the different species could be predicted and it was difficult to account for a variable atomic oxygen. 

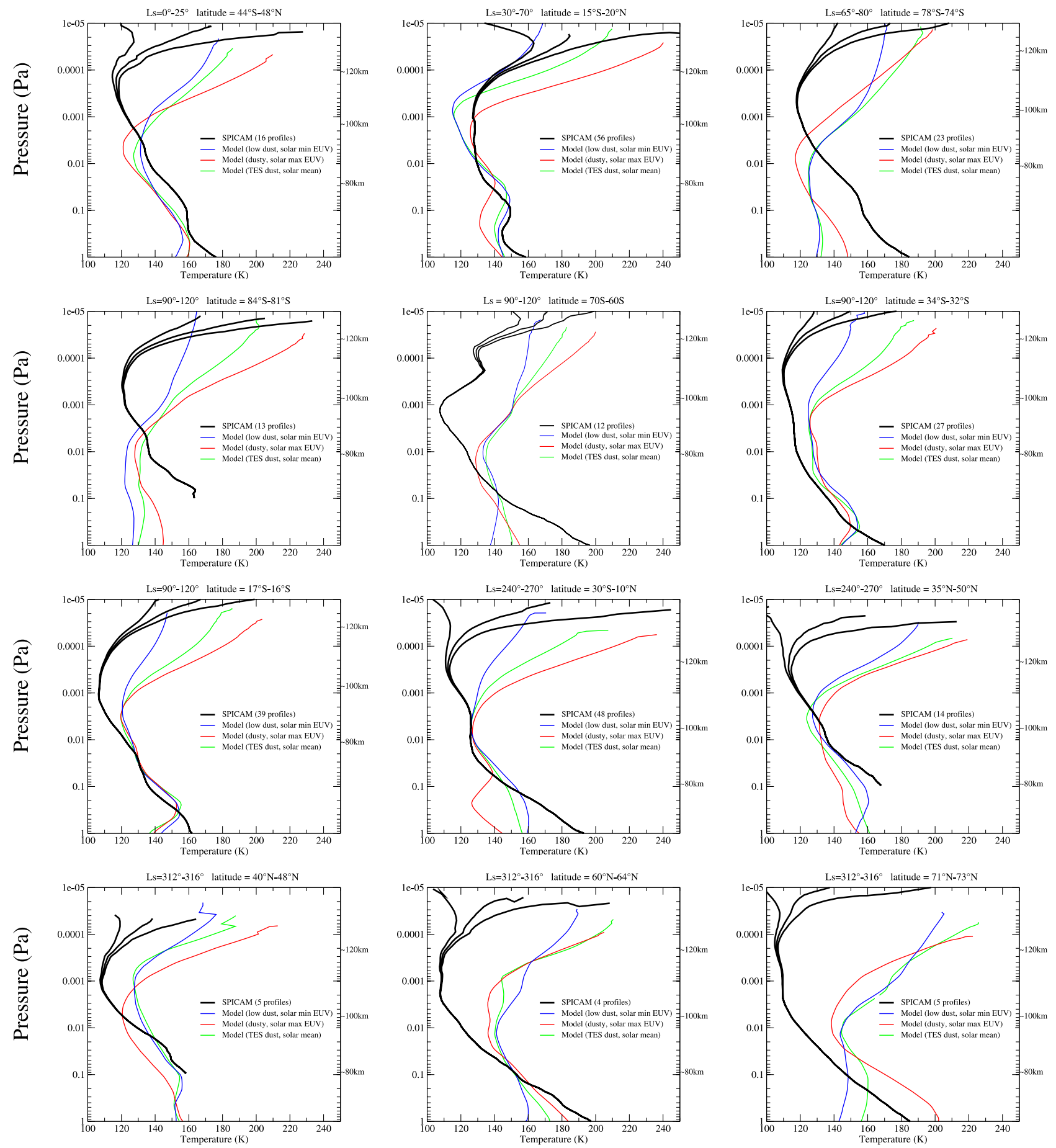

Figure 16. Average SPICAM temperature profiles as a function of pressure for selected season and latitudinal range, compared to GCM temperature profiles obtained at exactly the same location and time and similarly averaged. In each cases, three mean SPICAM profiles obtained assuming top temperatures of 100,175 , and $250 \mathrm{~K}$. are shown. The three GCM profiles correspond to various dust and solar EUV fluxes.

[28] However, the atomic oxygen is known to have an important effect on the $15 \mu \mathrm{m}$ cooling. The collisions with atomic oxygen excite the vibrational states of the $\mathrm{CO}_{2}$ molecule, enhancing the emission rate and the cooling [Bougher et al., 1994]. This can lead to variations of up to a factor 5 in the cooling when modifying the atomic oxygen profile, as shown by López-Puertas and LópezValverde, [1995]. Our most recent results obtained with the GCM photochemical scheme [González-Galindo et al., 2005] suggest that the fixed atomic oxygen profile used in the GCM could be significantly below the actual level. An underestimation of the atomic oxygen content implies an 


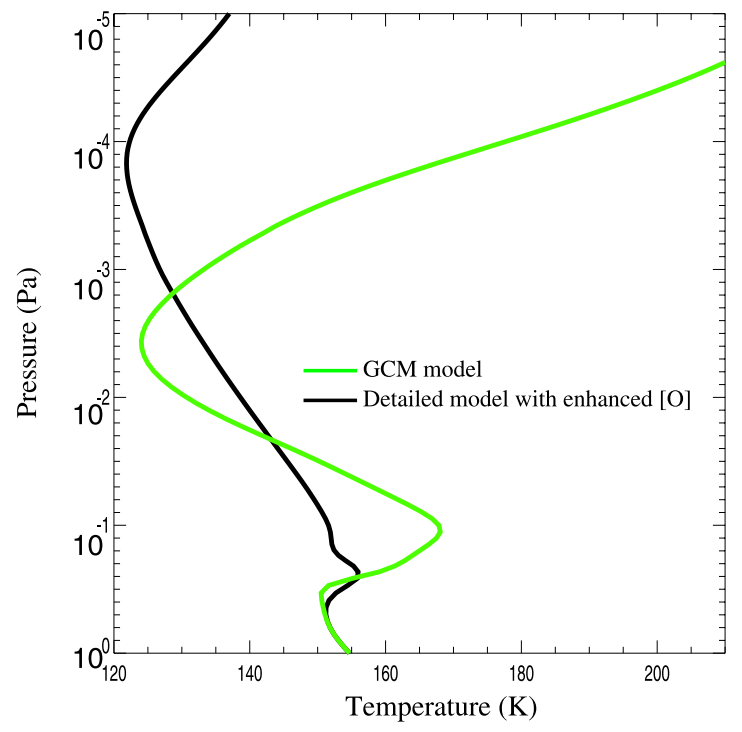

Figure 17. The impact of atomic oxygen on the temperature profile (simulated using the López-Valverde et al. [2006] 1-D model). Collision between atomic oxygen $\mathrm{O}$ and $\mathrm{CO}_{2}$ molecules can strongly enhance the $\mathrm{CO}_{2}$ infrared cooling and change the temperature profiles. Using a realistically enhanced profile of atomic oxygen concentration [O] (black line) rather than the [O] profile derived from Nair et al. [1994] assumed in the GCM (green line) allows reduction of the discrepancy between the model and the SPICAM observations shown in Figure 16 (see text for details).

overestimation of the temperatures, which could explain the differences with the observations.

[29] To check this hypothesis, we have used the 1-D model of the Martian atmosphere developed at the Instituto de Astrofísica de Andalucía [López-Valverde et al., 2006]. This model can simulate the $15 \mu \mathrm{m}$ cooling with both the parameterization included in the GCM (with the fixed atomic oxygen concentration) and the detailed NLTE scheme [López-Puertas and López-Valverde, 1995] on which the parameterization was based. This full model was able to use an enhanced atomic oxygen profile: mixing ratio of $210^{-2}$ below the homopause at $120 \mathrm{~km}$ and following the scale height of $\mathrm{O}$ above this level. This corresponds to a factor of 3 (at $200 \mathrm{~km}$ ) to 10 (at $120 \mathrm{~km}$ ) more than in the Nair et al. [1994] profile originally used for the GCM.

[30] We made two 10-day simulation (a steady state for the temperature is reached after 2-3 days of evolution) with both schemes. The final temperatures at LT $=0$ are represented in Figure 17. As can be seen, when using the detailed scheme with the improved atmospheric atomic oxygen concentration, the mesopause is at higher altitude and slightly cooler, and the temperatures in the lower thermosphere are significantly lower, improving the comparisons with SPICAM. Further analysis show that most of the difference is due to the change in atomic oxygen rather than in the model themselves. We conclude that a significant fraction of the differences between model and observations can be attributed to the fixed atomic oxygen in the $15 \mu \mathrm{m}$ cooling parameterization. We are currently working on a new $15 \mu \mathrm{m}$ cooling parameterization for the GCM that will include variable atomic oxygen following the photochemical model included in the GCM, as well as other improvements.

\section{Subfreezing Temperature at the Mesopause}

[31] As previously reported by Montmessin et al. [2006], some of the SPICAM temperature profiles exhibit temperatures at the mesopause well below the $\mathrm{CO}_{2}$ frost point. The 6 "coldest" (relatively to the $\mathrm{CO}_{2}$ condensation temperature) SPICAM profiles are shown in Figure 18. The $\mathrm{CO}_{2}$ frost point temperature $T_{c}$ can be calculated from the SPICAM data without any assumption on the $\mathrm{CO}_{2}$ mixing ratio. We used the following formula, adapted from Washburn [1948]: $T_{c}=-3148 . /(\ln (0.01 T \rho R)-23.102)$, with $\rho$ the observed $\mathrm{CO}_{2}$ density $\left(\mathrm{kg} \mathrm{m}^{-3}\right)$.

[32] In spite of the large absolute error bars and the coarse vertical resolution, several of the profiles are significantly below the condensation point, by as much as $24 \mathrm{~K}$. Such subfreezing temperatures were previously observed by Pathfinder during its entry [Schofield et al., 1997; Magalhães et al., 1999] and detected from Earth at submillimeter wavelengths [Clancy and Sandor, 1998]. The very high levels of supersaturation encountered suggest that in spite of the low pressure, $\mathrm{CO}_{2}$ ice clouds may form. Montmessin et al. [2006] analyzed four examples of SPICAM stellar occultation observations of unusual detached aerosol layers around $100 \mathrm{~km}$, thought to be clouds, and found that in each cases the simultaneous temperature measurements indicated subfreezing temperature a few kilometers above. Further analysis revealed cloud opacities in the subvisible range and ice crystals smaller than $100 \mathrm{~nm}$ in radius. More recently, spectroscopic evidence of $\mathrm{CO}_{2}$ ice clouds in the mesosphere of Mars have been found using the OMEGA imaging spectrometer [Montmessin et al., 2007]. The high altitude of the clouds could be estimated because $\mathrm{CO}_{2}$ ice was identified by its diagnostic reflectance signature at $4.26 \mu \mathrm{m}$, a spectral range dominated by gaseous $\mathrm{CO}_{2}$ absorption at lower altitude. In addition, a $\mathrm{CO}_{2}$ ice cloud could be observed simultaneously with its shadow on the ground. Geometrical considerations showed that the clouds were lying at an altitude of $80 \mathrm{~km}$. Most OMEGA data were analyzed, but such clouds were only observed in the nearequatorial regions, during two periods before and after northern summer solstice.

[33] Similarly, the subfreezing temperature profiles observed in the SPICAM data are not equally distributed. Figure 19 shows the minimum temperatures (relative to the $\mathrm{CO}_{2}$ frost point) in each SPICAM profiles, plotted as a function of season (Ls). Out of the 616 SPICAM profiles analysed in this paper, 45 profiles reveal locally temperature below the $\mathrm{CO}_{2}$ frost point. The spatial and temporal distribution of these profiles is shown in Figure 20. The coldest profiles are observed in early northern summer, which is consistent with the dayside OMEGA clouds observations. Unfortunately, there is no SPICAM data available in the areas where OMEGA observed most of its mesospheric clouds. The observations of cold temperature mostly in northern summer is also consistent with the subfreezing temperature observed around $80 \mathrm{~km}$ during Pathfinder descent entry at $\mathrm{Ls}=143^{\circ}$, at $3 \mathrm{am}$ local time 

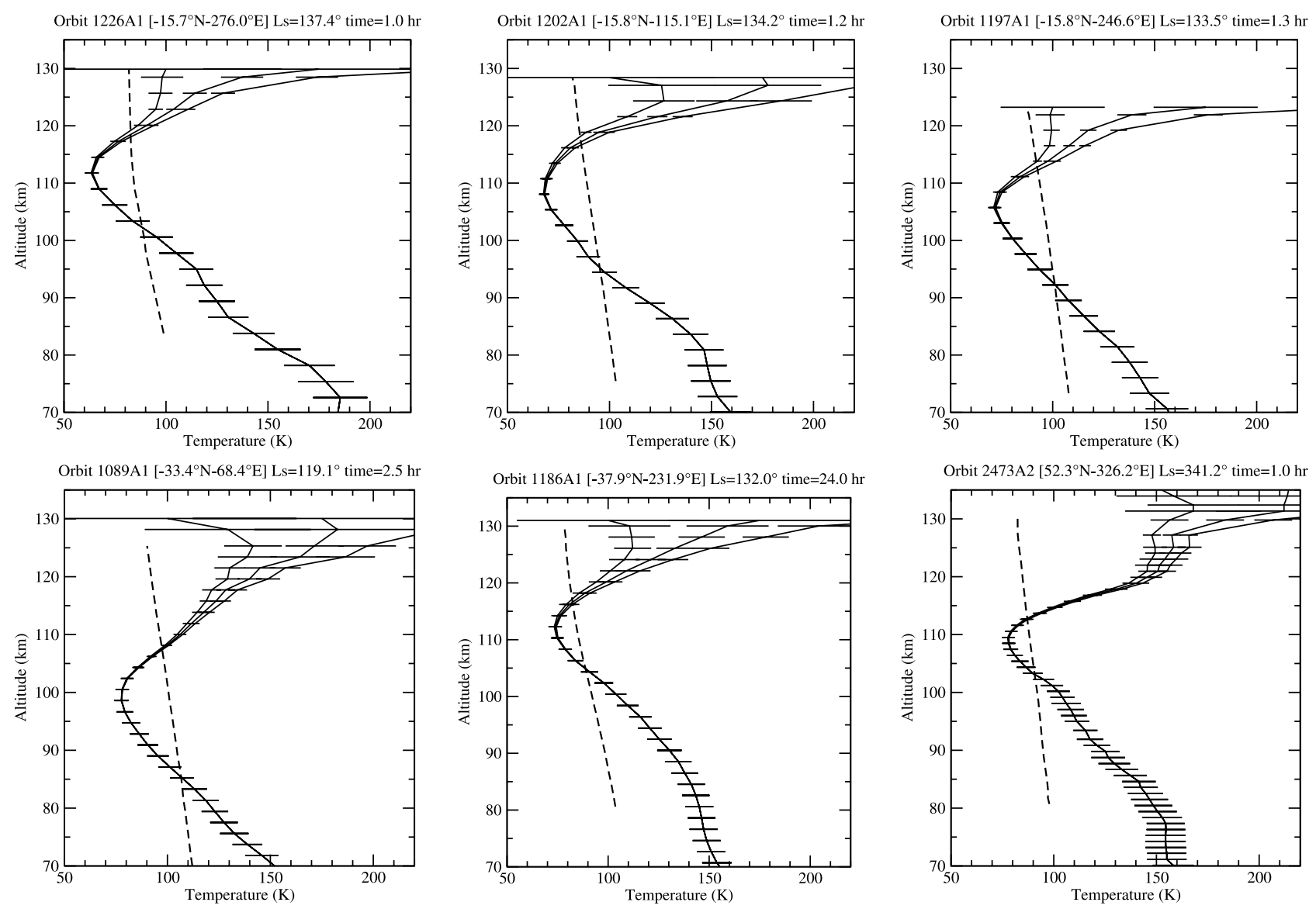

Figure 18. The six "coldest" temperature profiles (solid lines with error bars) observed by SPICAM, exhibiting temperature significantly below the $\mathrm{CO}_{2}$ frost point (dashed line).

(like many SPICAM observations), near $20^{\circ} \mathrm{N}$ which is plotted on Figure 20. Pathfinder entry profile is close to the cluster of cold points around $\mathrm{Ls}=120-150^{\circ}$, and particularly close to the 4 profiles found to be associated with a mesospheric cloud by Montmessin et al. [2006] (circles on Figure 20b). A map of the spatial distribution of SPICAM subfreezing profiles is shown on Figure 20a. No clear pattern can be identified, although the map would be consistent with a wave number 2 structure with two temperature minima around $90^{\circ} \mathrm{W}$ and $90^{\circ} \mathrm{E}$.

[34] The level of the cold mesopause (with mesopause temperatures plotted relative to the $\mathrm{CO}_{2}$ frost point) is shown on Figure 21. A wide range of values is observed, but the most supersaturated profiles tend to have their minimum in temperature around $0.001 \mathrm{~Pa}$ (around 90$100 \mathrm{~km})$.

\section{Conclusion}

[35] The new SPICAM data set on the middle atmosphere density and temperature reveals an atmosphere colder than expected, at least near the homopause and in the lower thermosphere. This is most likely due to underestimation of the atomic oxygen concentration in the existing atmospheric models. Between 70 and $130 \mathrm{~km}$, the density is directly connected to the lower atmosphere meteorology and dust content.
[36] The analysis presented in this paper remains preliminary. The large discrepancy found between general circulation models and observations has prevented us to conduct

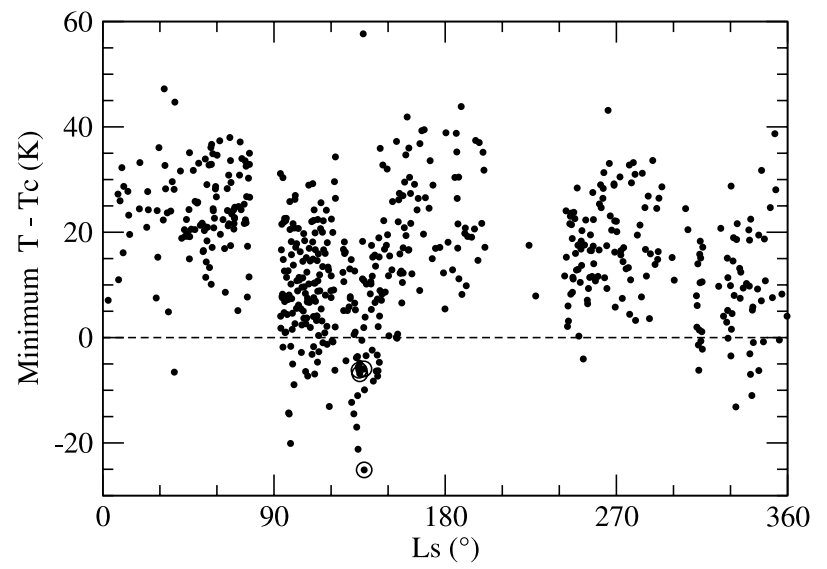

Figure 19. The minimum temperature $T$ (related to the $\mathrm{CO}_{2}$ frost point $T c$ ) encountered in each SPICAM profiles plotted as a function of season (Ls). A negative value correspond to a subfreezing profile. The four mesospheric clouds detected by SPICAM and thought to be high altitude $\mathrm{CO}_{2}$ ice clouds [Montmessin et al., 2006] are shown by circles. 
a)
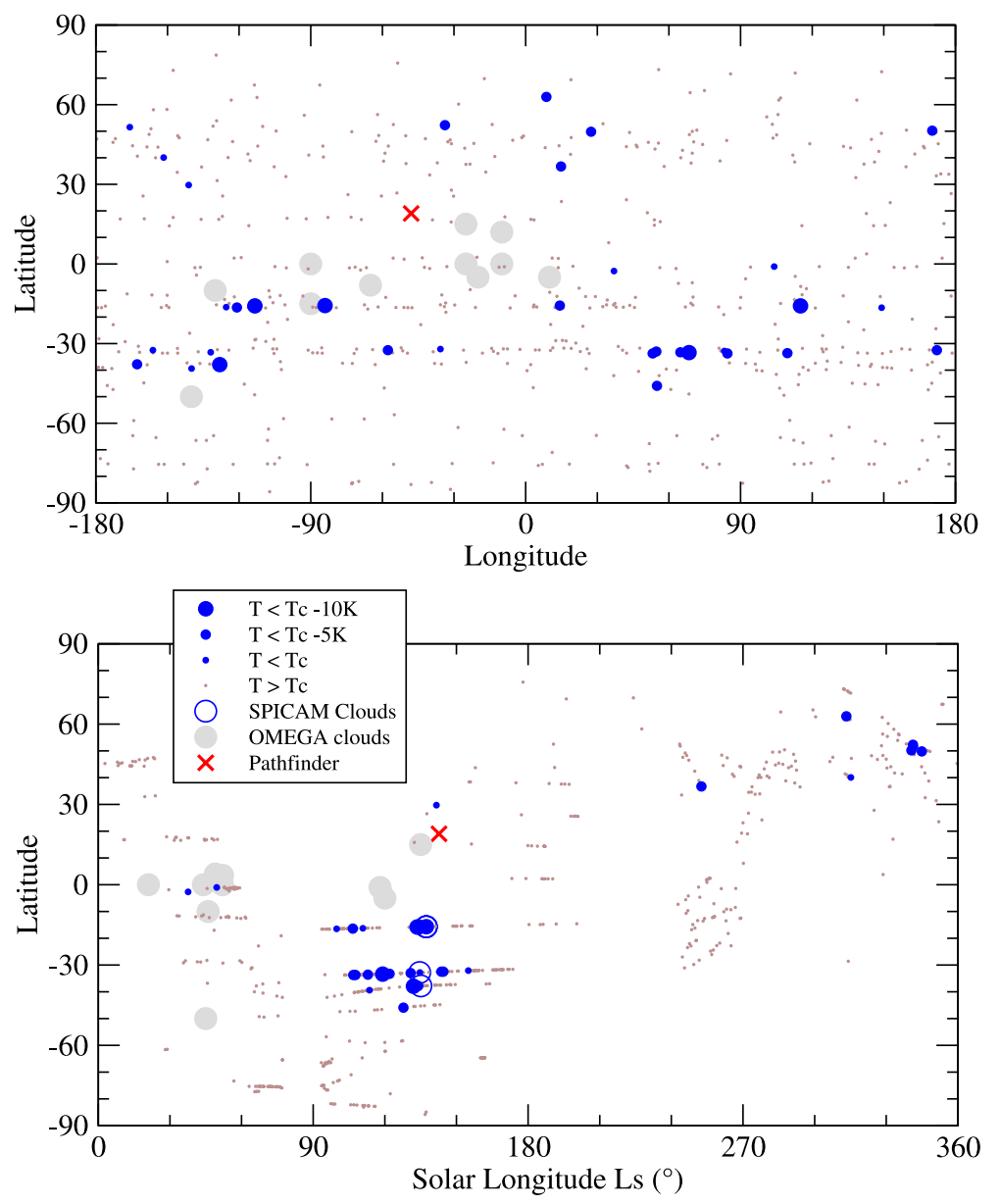

Figure 20. Seasonal and spatial distribution of the SPICAM temperature profiles exhibiting temperature below the $\mathrm{CO}_{2}$ frost point. The four mesospheric clouds detected by SPICAM and thought to be high altitude $\mathrm{CO}_{2}$ ice clouds [Montmessin et al., 2006] are shown by blue circles. The location of the dayside $\mathrm{CO}_{2}$ ice clouds imaged by OMEGA [Montmessin et al., 2007] are identified by grey shaded circles. The Pathfinder entry profile which also exhibited subfreezing temperatures is marked by a red cross.

a detailed analysis of the variability in the observations. In the future, we plan to further improve the radiative transfer model used in our retrieval scheme and hope to have access to spectroscopic data suitable for low temperature atmospheres. We also look forward to the opportunity of performing further validations with other simultaneous measurements. Preliminary comparison with in situ accelerometer measurements [Theriot et al., 2006] seems to confirm the accuracy of the SPICAM density measurements. Besides, the observations of $\mathrm{CO}_{2}$ ice mesospheric clouds by SPICAM and OMEGA [Montmessin et al., 2006, 2007] confirm the existence of subfreezing temperature as observed by SPICAM. In the future, we look forward to comparing the Mars Climate Sounder data [McCleese et al., 2007] around 70 to $80 \mathrm{~km}$ with the SPICAM data to further validate our results, and help interpret the low density often observed at $70 \mathrm{~km}$ which suggest a atmosphere colder than expected between 40 and $70 \mathrm{~km}$ (section 7.2). We will also extend our investigation to the occultation profiles obtained after the last orbit considered for use in the present paper

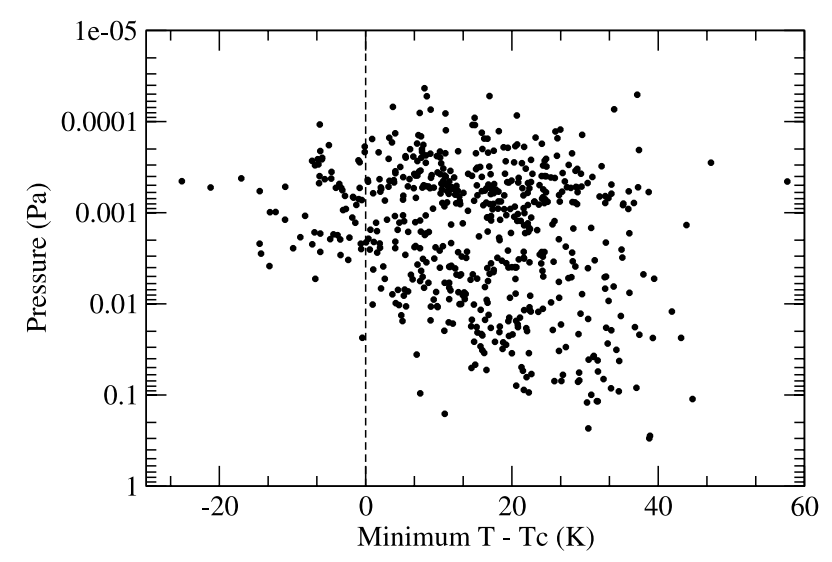

Figure 21. Pressure level of the mesopause, with mesopause temperatures plotted relative to the $\mathrm{CO}_{2}$ frost point, in all SPICAM temperature profiles. 
(orbit 2980) obtained on 5 June 2006. For information, 276 new stellar occultations were performed between this date and 19 November 2007 (not all these profiles will be usable for temperature and density retrieval, however).

[37] Acknowledgments. We thank P. Thollot for his work on radiative transfer uncertainties; E. Millour, L. Montabone, A. Spiga, J.B. Madeleine S. Bougher and T. McDunn for useful discussions; and two anonymous reviewers for constructive reviews. We also wish to thank the SPICAM and Mars Express engineering teams for their excellent work and support.

\section{References}

Angelats i Coll, M., F. Forget, M. A. López-Valverde, P. L. Read, and S. R. Lewis (2004), Upper atmosphere of Mars up to $120 \mathrm{~km}$ : Mars Global Surveyor accelerometer data analysis with the LMD general circulation model, J. Geophys. Res., 109, E01011, doi:10.1029/2003JE002163.

Angelats i Coll, M., F. Forget, M. A. López-Valverde, and F. GonzálezGalindo (2005), The first Mars thermospheric general circulation model: The Martian atmosphere from the ground to $240 \mathrm{~km}$, Geophys. Res. Lett., 32, L04201, doi:10.1029/2004GL021368.

Bertaux, J.-L., et al. (2006), SPICAM on Mars Express: Observing modes and overview of UV spectrometer data and scientific results, $J$. Geophys. Res., 111, E10S90, doi:10.1029/2006JE002690.

Bougher, S. W., D. M. Hunten, and R. G. Roble (1994), $\mathrm{CO}_{2}$ cooling in terrestrial planet thermospheres, J. Geophys. Res., 99, 14,609-14,622.

Bougher, S. W., S. Engel, R. G. Roble, and B. Foster (1999), Comparative terrestrial planet thermospheres: 2 . Solar cycle variation of global structure and winds at equinox, J. Geophys. Res., 104, 16,591-16,611.

Bougher, S. W., J. M. Bell, J. R. Murphy, M. A. López-Valverde, and P. G. Withers (2006), Polar warming in the Mars thermosphere: Seasonal variations owing to changing insolation and dust distributions, Geophys. Res. Lett., 33, L02203, doi:10.1029/2005GL024059.

Bougher, S. W., J. M. Bell, B. Steers, J. R. Murphy, and G. M. Keating (2007), Winter polar warming in the Mars thermosphere, in Seventh International Conference on Mars, Abstract 3027, Jet Propul. Lab., Pasadena, Calif

Clancy, R. T., and B. J. Sandor (1998), $\mathrm{CO}_{2}$ ice clouds in the upper atmosphere of Mars, Geophys. Res. Lett., 25, 489-492.

Clancy, R. T., B. J. Sandor, M. J. Woff, P. R. Christensen, M. D. Smith, J. C. Pearl, B. J. Conrath, and R. J. Wilson (2000), An intercomparison of ground-based millimeter, MGS TES, and Viking atmospheric temperature measurements: Seasonal and interannual variability of temperatures and dust loading in the global Mars atmosphere, J. Geophys. Res., 105, 9553-9571.

Forbes, J. M., and M. E. Hagan (2000), Diurnal Kelvin wave in the atmosphere of Mars: Toward and understanding of "stationary" density structures observed by the MGS accelerometer, Geophys. Res. Lett., 27, $3563-3566$

Forbes, J. M., A. F. C. Bridger, S. W. Bougher, M. E. Hagan, J. L. Hollingsworth, G. M. Keating, and J. Murphy (2002), Nonmigrating tides in the thermosphere of Mars, J. Geophys. Res., 107(E11), 5113, doi:10.1029/2001JE001582.

Forget, F., F. Hourdin, R. Fournier, C. Hourdin, O. Talagrand, M. Collins, S. R. Lewis, P. L. Read, and J.-P. Huot (1999), Improved general circulation models of the Martian atmosphere from the surface to above $80 \mathrm{~km}$, J. Geophys. Res., 104, 24,155-24,176.

González-Galindo, F., M. A. López-Valverde, M. Angelats i Coll, and F. Forget (2005), Extension of a Martian general circulation model to thermospheric altitudes: UV heating and photochemical models, J. Geophys. Res., 110, E09008, doi:10.1029/2004JE002312.

Grassi, D., C. Fiorenza, L. V. Zasova, N. I. Ignatiev, A. Maturilli, V. Formisano, and M. Giuranna (2005), The Martian atmosphere above great volcanoes: Early planetary Fourier spectrometer observations, Planet. Space Sci., 53, 1053-1064.

Hinson, D. P., M. D. Smith, and B. J. Conrath (2004), Comparison of atmospheric temperatures obtained through infrared sounding and radio occultation by Mars Global Surveyor, J. Geophys. Res., 109, E12002, doi:10.1029/2004JE002344.

Keating, G. M., et al. (1998), The structure of the upper atmosphere of mars: In situ accelerometer measurements from Mars Global Surveyor, Science, 279, 1672-1676.

Keating, G. M., M. Theriot Jr., R. Tolson, S. Bougher, F. Forget, and J. Forbes (2003), Global Measurements of the Mars Upper Atmosphere: In Situ Accelerometer Measurements from Mars Odyssey 2001 and Mars Global Surveyor, Lunar Planet. Sci., XXXIV, 1142.

Keating, G. M., S. W. Bougher, M. E. Theriot, R. H. Tolson, R. W. Zurek, R. C. Blanchard, J. R. Murphy, and J.-L. Bertaux (2007), Mars neutral
Uupper atmosphere temporal and spatial variations discovered from the accelerometer science experiment aboard Mars Reconnaissance Orbiter, Lunar Planet. Sci, XXXVIII, 2074.

Korablev, O. I., J.-L. Bertaux, and J.-P. Dubois (2001), Occultation of stars in the UV: Study of the atmosphere of Mars, J. Geophys. Res., 106, $7597-7610$.

Lebonnois, S., E. Quémerais, F. Montmessin, F. Lefévre, S. Perrier, J.-L. Bertaux, and F. Forget (2006), Vertical distribution of ozone on Mars as measured by SPICAM/Mars Express using stellar occultations, J. Geophys. Res., 111, E09S05, doi:10.1029/2005JE002643.

López-Puertas, M., and M. López-Valverde (1995), Radiative energy balance of $\mathrm{CO}_{2}$ non-LTE infrared emissions in the Martian atmosphere, Icarus, 114, 113-129.

López-Valverde, M. A., and M. Lopez-Puertas (2001), Amospheric non-lte effects and their parameterization for mars, ESA Contract 11369 Technical Report, Eur. Space Agency, Paris.

López-Valverde, M. A., D. P. Edwards, M. López-Puertas, and C. Roldán (1998), Non-local thermodynamic equilibrium in general circulation models of the Martian atmosphere: 1. Effects of the local thermodynamic equilibrium approximation on thermal cooling and solar heating, J. Geophys. Res., 103, 16,799-16,811.

López-Valverde, M. A., F. González-Galindo, and F. Forget (2006), 1-D and 3-D modelling of the upper atmosphere of Mars, in Mars Atmosphere Modelling and Observations, edited by F. Forget, et al., p. 623, Eur. Space Agency, Paris.

Magalhães, J. A., J. T. Schofield, and A. Seiff (1999), Results of the Mars Pathfinder atmospheric structure investigation, J. Geophys. Res., 104, $8943-8956$

McCleese, D. J., J. T. Schofield, F. W. Taylor, S. B. Calcutt, M. C. Foote, D. M. Kass, C. B. Leovy, D. A. Paige, P. L. Read, and R. W. Zurek (2007), Mars Climate Sounder: An investigation of thermal and water vapor structure, dust and condensate distributions in the atmosphere, and energy balance of the polar regions, J. Geophys. Res., 112, E05S06, doi:10.1029/2006JE002790

Millour, E. et al. (2007), The Mars climate database, version 4.2, paper presented at European Mars Science and Exploration Conference, ESTEC, Noordwijk, Netherlands, 12-16 Nov.

Montabone, L., S. R. Lewis, P. L. Read, and D. P. Hinson (2006), Validation of Martian meteorological data assimilation for MGS/TES using radio occultation measurements, Icarus, 185, 113-132.

Montmessin, F., et al. (2006), Subvisible $\mathrm{CO}_{2}$ ice clouds detected in the mesosphere of Mars, Icarus, 183, 403-410.

Montmessin, F., B. Gondet, J.-P. Bibring, Y. Langevin, P. Drossart, F. Forget, and T. Fouchet (2007), Hyperspectral imaging of convective $\mathrm{CO} 2$ ice clouds in the equatorial mesosphere of Mars, J. Geophys. Res., 112, E11S90, doi:10.1029/2007JE002944.

Nair, H., M. Allen, A. D. Anbar, Y. L. Yung, and R. T. Clancy (1994), A photochemical model of the Martian atmosphere, Icarus, 111, 124-150.

Pätzold, M., S. Tellmann, B. Häusler, D. Hinson, and G. L. Tyler (2006), Radio-sounding of the neutral Martian atmosphere with Mars Express: Overview of the observations, in Mars Atmosphere Modelling and Observations, edited by F. Forget, et al., p. 132, Eur. Space Agency, Paris.

Quémerais, E., J.-L. Bertaux, O. Korablev, E. Dimarellis, C. Cot, B. R. Sandel, and D. Fussen (2006), Stellar occultations observed by SPICAM on Mars Express, J. Geophys. Res., 111, E09S04, doi:10.1029/ 2005JE002604.

Schofield, J. T., D. Crisp, J. R. Barnes, R. M. Haberle, J. A. Magalhaães, J. R. Murphy, A. Seiff, S. Larsen, and G. Wilson (1997), The Mars Pathfinder Atmospheric Structure Investigation/Meteorology (ASI/ MET) experiment, Science, 278, 1752-1757.

Seiff, A., and D. B. Kirk (1977), Structure of the atmosphere of Mars in summer mid-latitudes, J. Geophys. Res., 82, 4364-4378.

Smith, D. E., et al. (2001), Mars Orbiter Laser Altimeter: Experiment summary after the first year of global mapping of Mars, J. Geophys. Res., 106, 23,689-23,722.

Smith, M. D. (2004), Interannual variability in TES atmospheric observations of Mars during 1999-2003, Icarus, 167, 148-165.

Smith, M. D., J. C. Pearl, B. J. Conrath, and P. R. Christensen (2001), Thermal Emission Spectrometer results: Mars atmospheric thermal structure and aerosol distribution, J. Geophys. Res., 106, 23,929-23,945.

Smith, M. D., M. J. Wolff, N. Spanovich, A. Ghosh, D. Banfield, P. R Christensen, G. A. Landis, and S. W. Squyres (2006), One Martian year of atmospheric observations using MER Mini-TES, J. Geophys. Res., 111, E12S13, doi:10.1029/2006JE002770.

States, R. J., and C. S. Gardner (2000), Thermal structure of mesopause region $(80-105 \mathrm{~km})$ at $40^{\circ} \mathrm{N}$ latitude, Part I: Seasonal variations, J. Atmos. Sci., 57, 66-77.

Stewart, A. I. F., M. J. Alexander, R. R. Meier, L. J. Paxton, S. W. Bougher, and C. G. Fesen (1992), Atomic oxygen in the Martian thermosphere, J. Geophys. Res., 97, 91-102. 
Theriot, M., G. Keating, R. Blanchard, S. Bougher, R. Zurek, R. Tolson, J. Murphy, F. Forget, and J. Bertaux (2006), Interannual Comparison of Temporal and Spatial Structure in the Martian Thermosphere from Atmospheric Accelerometer Measurements of Mars Reconnaissance Orbiter (MRO) during Aerobraking and Stellar Occultation Measurements from the SPICAM Ultraviolet Infrared Atmospheric Spectrometer of Mars Express (MEX), paper presented at 38th Meeting of the Division of Planetary Sciences of the American Astronomical Society, Pasadena, Calif.

Tikhonov, A. N., and V. Y. Arsenin (1977), Solutions of Ill Posed Problems, V. H. Winston, New York.

von Zahn, U., and J. Höffner (1996), Mesopause temperature profiling by potassium lidar, Geophys. Res. Lett., 23, 141-144.

Washburn, E. (1948), International Critical Tables of Numerical Data, Physics, Chemistry, and Technology, vol. 3, McGraw-Hill, New York.

Wilson, R. J. (2002), Evidence for nonmigrating thermal tides in the Mars upper atmosphere from the Mars Global Surveyor Accelerometer Experiment, Geophys. Res. Lett., 29(7), 1120, doi:10.1029/2001GL013975.
Withers, P., and M. D. Smith (2006), Atmospheric entry profiles from the Mars Exploration Rovers Spirit and Opportunity, Icarus, 185, 133-142. Yoshino, K., J. R. Esmond, Y. Sun, W. H. Parkinson, K. Ito, and T. Matsui (1996), Absorption cross section measurements of carbon dioxide in the wavelength region $118.7-175.5 \mathrm{~nm}$ and the temperature dependence, J. Quant. Spectrosc. Radiat. Transfer, 55, 53-60.

Zurek, R. W., J. R. Barnes, R. M. Haberle, J. B. Pollack, J. E. Tillman, and C. B. Leovy (1992), Dynamics of the atmosphere of Mars, in Mars, pp. 835-933, Univ. of Ariz. Press, Tucson.

F. Forget, F. González-Galindo, and S. Lebonnois, Laboratoire de Meteorologie Dynamique, IPSL Universite Paris 6, BP99, 4 place Jussieu, F-75005 Paris, France. (forget@lmd.jussieu.fr)

J.-L. Bertaux, E. Dimarellis, F. Montmessin, E. Quémerais, and A. Reberac, Service d'Aéronomie, IPSL, Reduit de Verriéres, BP3, Route des Gatines, F-91271 Verrières-le-Buisson, France.

M. A. López-Valverde, Instituto de Astrofísica de Andalucía, CSIC, Apdo 3004, E-18080 Granada, Spain. 